\title{
Disrupted choline clearance and sustained acetylcholine release in vivo by a common choline transporter coding variant associated with poor attentional control in humans
}

Eryn Donovan ${ }^{1}$, Cassandra Avila ${ }^{1}$, Vinay Parikh², Cristina Fenollar-Ferrer ${ }^{3}$, Randy D. Blakely ${ }^{4}$, Martin Sarter ${ }^{5, *}$

${ }^{1}$ Department of Psychology, University of Michigan, Ann Arbor, MI, USA; ${ }^{2}$ Department of Psychology \& Neuroscience Program, Temple University, Philadelphia, PA, USA; ${ }^{3}$ Section of Human Genetics, National Institute of Deafness and Other Communication Disorders, Bethesda, MD, USA; ${ }^{4}$ Stiles-Nicholson Brain Institute and Department of Biomedical Science, Charles E. Schmidt College of Medicine, Florida Atlantic University, Jupiter, FL, USA; ${ }^{5}$ Department of Psychology, Neuroscience Program and Department of Neurology, University of Michigan, Ann Arbor, MI, USA

Number of figures: 8

Number of words: Abstract: 245/250; Significance Statement: 120/120; Introduction: 631/650; Discussion: $1,134 / 1,500$

Conflict of Interest Statement: On behalf of all authors, the corresponding author states that there is no conflict of interest. The research described in this manuscript was supported in part by PHS grant R01DA045063 (MS) and by University of Michigan funds to MS.

Author contributions: ED and CA conducted the electrochemical experiments and analyzed the data. VP conducted immunoblotting experiments and analyzed the data. RDB generated the CHT Val89 mice and provided founders for the CHT Val89 breeding colony at the University of Michigan. ED, VP, RDB and MS designed the experiments. CFF developed the structural model of the CHT Val89 mutation. ED, CFF, RDB and MS wrote the original draft of the paper. All authors contributed to the editing of the final manuscript.

Acknowledgement: We thank Evan Haley (Temple University) for assistance with subcellular fractionation and immunoblotting studies.

${ }^{\star}$ Corresponding author: Martin Sarter, University of Michigan, Dept. of Psychology, 530 Church Street, Ann Arbor, MI 48109; phone: 734-764-6392; email: msarter@umich.edu 


\section{Abstract}

Transport of choline via the neuronal high-affinity choline transporter (CHT; SLC5A7) is essential for cholinergic terminals to synthesize and release acetylcholine (ACh). In humans, we previously demonstrated an association between a common CHT coding substitution (rs1013940; Ile89Val) and reduced attentional capacity as well as attenuated frontal cortex activation. Here, we used a CRISPR/Cas9 approach to generate mice expressing the $189 \mathrm{~V}$ substitution and assessed, using in vivo cortical choline biosensing, CHT-mediated choline transport, and ACh release. CHTmediated clearance of choline in mice expressing one or two Val89 alleles was reduced by over 7-fold relative to wild type (WT) mice, suggesting dominant-negative effects. Choline clearance in CHT Val89 mice was further reduced by neuronal inactivation. Deficits in ACh release, 5 and 10 min after repeated depolarization at a low, behaviorally relevant frequency, support an attenuated reloading capacity of cholinergic neurons in mutant mice. The density of CHTs in total synaptosomal lysates and neuronal plasma-membrane-enriched fractions was not impacted by the Val89 variant, indicating a selective impact on CHT function. Consistent with this hypothesis, structural modeling revealed that Val89 may attenuate choline transport by changing the ability of choline to induce conformational changes of $\mathrm{CHT}$ that support normal transport rates. Our findings suggest that diminished, sustained cholinergic signaling capacity in the frontal cortex underlies perturbed attentional performance in individuals expressing CHT Val89. Our work supports the utility of the $\mathrm{CHT}$ Val89 mouse model as a valuable model to study heritable risk for cognitive disorders arising from cholinergic dysfunction.

Key words: choline transporter; rs1013940; choline clearance; acetylcholine; amperometry; attention; transgenic mouse

\section{Significance Statement}

Acetylcholine (ACh) signaling depends on the capacity of the neuronal choline transporter (CHT) to import choline into presynaptic terminals for ACh synthesis. Previous research demonstrated that humans expressing the common CHT coding variant Val89 exhibit attentional vulnerabilities and attenuated fronto-cortical activation during attention. Here, we find that mice engineered to express the Val89 variant exhibit reduced CHT-mediated choline clearance in frontal cortex and a diminished capacity to sustain neuronal ACh release. These findings provide a mechanistic framework for interpreting the attentional phenotype associated with the human Val89 variant and establish a mouse model that permits a more invasive interrogation of CNS effects as well as the 
development of therapeutic strategies tailored to those, including Val89 carriers, with presynaptic cholinergic perturbations.

\section{Introduction}

Activation of forebrain cholinergic projection systems is necessary for a wide range of perceptualattentional functions. In humans, disruption of ACh signaling, either by pharmacological blockade of cholinergic receptors or as a result of cholinergic cell loss, impairs the capacity to select behaviorally significant stimuli for behavioral control, to filter distractors, and to perform under dual-task conditions (e.g., Thienel et al., 2009; Mentis et al., 2001; Kim et al., 2019; Albin et al., 2018; Yarnall et al., 2011; Perry and Hodges, 1999). Results from experiments in non-human primates and rodents have confirmed the essential role of forebrain cholinergic activity for performing a broad range of attentional tasks (e.g., Muir et al., 1992; Voytko et al., 1994; McGaughy et al., 1996; Turchi and Sarter, 2000, 1997) and specified underlying cholinergic signaling characteristics and postsynaptic mechanisms (e.g., Venkatesan and Lambe, 2020; Howe et al., 2017; Gritton et al., 2016; Chen et al., 2015; Parikh et al., 2007; Sarter and Lustig, 2020; Nair et al., 2018; Laszlovszky et al., 2020).

The sodium-dependent, high-affinity, neuronal choline transporter (CHT) is essential for sustaining the capacity of presynaptic cholinergic neurons to synthesize and release ACh (Yamamura and Snyder, 1972; Guyenet et al., 1973; Simon et al., 1976; Ennis and Blakely, 2016). Early experiments assessing the effects of pharmacological blockade of the CHT with the competitive $\mathrm{CHT}$ antagonist hemicholinium-3 (HC-3), and more recent investigations into the impact of CHT heterozygosity in transgenic mice, have demonstrated that reduced CHT capacity causes attenuated cholinergic signaling and broadly disrupts perceptual-attentional functions (for reviews see Ferguson and Blakely, 2004; Sarter and Parikh, 2005; Bazalakova and Blakely, 2006; Sarter et al., 2016), as well as changes in peripheral autonomic function (English et al., 2010). Reduced CHT capacity may result from attenuated substrate binding and internalization as well as from disrupted intracellular trafficking of the CHT (e.g., Koshy Cherian et al., 2017; Ferguson et al., 2003).

Okuda et al. (2002) discovered a common, single nucleotide polymorphism (SNP) within human CHT coding sequences (rs1013940) that produces the lle89Val or I89V substitution in transmembrane domain 3, with an 8-10\% minor allele frequency in Caucasians. Importantly, expression of the Val89 variant in transfected cells demonstrated reduced choline transport (40- 
$50 \%$ of WT CHT) without changes in transporter surface expression or substrate affinity. We previously demonstrated that humans heterozygous for the Val89 variant exhibited attention deficits (Berry et al., 2015; Berry et al., 2014; Sarter et al., 2016). These subjects self-reported heightened distractibility and exhibited robustly higher distractor vulnerability than subjects expressing the major lle89 allele. Moreover, right frontal activation during an attention-demanding task was significantly attenuated in these individuals (see also Gorka et al., 2015). Clinical significance of the expression of the $\mathrm{CHT}$ Val89 variant was indicated by studies showing an association with attention-deficit hyperactivity disorder (English et al., 2009) and major depression (Hahn et al., 2008).

The current experiments aimed to determine, in vivo, the impact of the CHT Val89 variant on cortical choline transport and $\mathrm{ACh}$ release when introduced into mouse $\mathrm{CHT}$ coding sequences using CRISPR/Cas9 methods. Using these mutant mice and their lle89 (WT) littermates, we establish a significant reduction in the capacity of Val89-expressing mice to clear choline from the extracellular space. Furthermore, successive, depolarization-evoked ACh release events, induced at a frequency mirroring cholinergic activity in attention task-performing rodents, led to a robust attenuation of $A C h$ release in the mutant mice. These cholinergic capacity limits by the CHT Val89 variant were not associated with altered surface expression of the transporter. Structural modeling studies suggested that the Val89 substitution may reduce choline transport by disrupting the exposure of the $\mathrm{CHT}$ substrate binding site. Our findings provide a neurobiological framework for the inattentive phenotype that characterizes human Val89 carriers and raises the possibility that additional autonomic and immunological functions are modified in humans expressing this $\mathrm{CHT}$ variant.

\section{Materials and Methods}

\section{Subjects}

Mice were generated to express a valine rather than the WT isoleucine residue at amino acid 89 in the endogenous S/c5a7 gene that encodes the CHT. Briefly, a CRISPR/Cas9 approach (Cong et al., 2013) was implemented through the Transgenic Mouse Embryonic Stem Cell Shared Resource facility at Vanderbilt University. An RNA guide expressing construct was developed by ligation of a $193 \mathrm{bp}$ protospacer into the Bbsl sites of the pX330 plasmid (http://www.addgene.org/42230/) that also affords expression of human codon optimized Cas9. The protospacer contains an 82-nucleotide arm 5' of the codon (ATT) that encodes lle89 in exon 
3 and a 93-nucleotide arm 3' of the site in intron 4 (HDR oligos). An 18mer donor oligonucleotide (5'CCㅌGGGㅡㄴTTTCTCTGAGTC3') was generated to encode a Val89 codon along with the

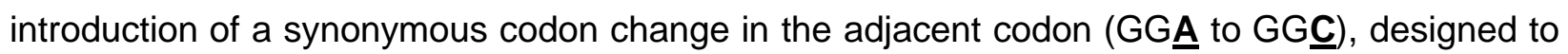
reduce the chance of repeated CRISPR activity on the edited sequence. Base changes also afford diagnostic restriction digestion (novel Hpy99l site) to ascertain the presence of the sequence change introduced. Cas9/gRNA plasmid and donor oligonucleotide were injected into single cell C57BL6/J mouse embryos subsequently implanted into a pseudopregnant female mouse. After weaning, tissue from tail samples of pups were genotyped by restriction digest, followed by DNA sequencing of PCR fragments spanning the mutation, cloned into pGEMTEasy (Promega). From 3 different litters, 3 animals were identified as heterozygous founders carrying the intended codon mutation without other deletions apparent. Two of these founders produced pups carrying the Val89 allele, one of which served as the founder for the line studied. These animals were subsequently crossed to wild type C57BL6/J mice for eight generations before maintaining the colony as homozygous or heterozygous breeders.

A total of $\mathrm{N}=80$ mice ( $\mathrm{n}=26 \mathrm{WT}$ ( $\mathrm{CHT} \mathrm{T}^{\text {lle/lle }}$, henceforth termed WT; 13 females), $\mathrm{n}=26$ heterozygous ( $\mathrm{CHT}^{\mathrm{Ile} / \mathrm{Val}}$, henceforth termed $\mathrm{CHT} \mathrm{I} \mathrm{V} ; 12$ females), and 28 homozygous ( $\mathrm{CHT}^{\mathrm{Va} / \mathrm{Val}}$, henceforth termed CHT V/V; 13 females) mice were included in the final analyses. Following arrival at the University of Michigan, the CHT Val89 colony was further crossed to C57BL/6J mice for an additional four generations. Mice were housed in a temperature and humidity-controlled environment $\left(23^{\circ} \mathrm{C}, 45 \%\right)$ with a $12: 12$ hour light/dark cycle (lights on at 7:00 A.M.). Data collection for all experiments began during the light phase. Litters were weaned at 3 weeks and grouphoused with same-sex siblings for a maximum of 6 animals per cage. Genomic DNA from tail tissue samples was used to determine mouse genotype as either WT, CHT I/V or CHT V/V by Transnetyx (Cordova, TN). Animals were given food (Envigo Teklad rodent diet) and water ad libitum. Mice were a minimum of 8 weeks old at the beginning of experiments. All procedures were conducted in adherence with protocols approved by the Institutional Animal Care and Use Committee (IACUC) at the University of Michigan.

Mice used in individual experiments. Amperometric recordings of in vivo choline clearance were used to quantify the impact of the Val89 variant on $\mathrm{CHT}$ uptake efficiency under various conditions. Initial experiments determined exogenous choline clearance in WT ( $n=4,3$ females), $\mathrm{CHT} \mathrm{I/V} \mathrm{(} \mathrm{n}=4,1$ female), and CHT V/V ( $\mathrm{n}=5,2$ females) mice. A total of 14 additional mice (6 females) were used to determine choline clearance in the presence of the CHT competitive inhibitor HC-3 ( $n=5$ WT, n=4 CHT I/V, n=6 CHT V/V; 2 females for each genotype). In separate 
mice ( $n=6,2$ per genotype, 1 female per genotype), the contribution of diffusion rate to overall choline clearance was quantified in the presence of lidocaine $\mathrm{HCl}$ to arrest transporter activity and, more broadly, neuronal firing (Tehovnik and Sommer, 1997; Malpeli and Schiller, 1979; Chu and Lee, 1994). To illustrate the efficacy of lidocaine, we also determined endogenous ACh release in the presence of lidocaine in one WT male mouse. To demonstrate attenuated ACh release following repeated potassium-evoked depolarizations, a total of 15 mice were used (WT, $\mathrm{n}=4$, 2 females; CHT I/V, n=6, 3 females; CHT V/V, $n=5,3$ females). A final group of 30 mice (equal group sizes and sex distribution across genotypes) were used to assess CHT densities in total synaptosomal lysates and synaptosomal plasma membrane-enriched fractions.

\section{Amperometric recordings of choline currents}

The main experiments described herein measured choline concentrations in the extracellular space, following pressure ejections of choline to determine CHT-mediated choline clearance, and following pressure ejections of $\mathrm{KCl}$ to measure choline transients reflecting newly released $\mathrm{ACh}$ that was hydrolyzed by endogenous acetylcholinesterase (AChE). Numerous prior experiments validated the use of choline-sensitive microelectrodes to monitor ACh release in real-time, in part by demonstrating that endogenous AChE completely hydrolyzes new released ACh (Parikh et al., 2013; Giuliano et al., 2008; Parikh et al., 2007; Parikh and Sarter, 2006; Parikh et al., 2004).

Choline concentrations were measured using an amperometric measurement scheme, illustrated in Figure 1. In this approach, choline oxidase (CO) is immobilized onto the surface of an electrode to oxidize choline, resulting in a byproduct of hydrogen peroxide. Electrochemical oxidation of hydrogen peroxide then results in the release of two electrons, which generate the current that is translated into the concentration of choline at the recording site based on prior in vitro calibrations (Burmeister et al., 2003; Burmeister et al., 2000).

The construction of choline sensors and the amperometric measurement scheme were detailed previously (references above). Briefly, four platinum-iridium (Pt/lr) recording sites (15 x $333 \mu \mathrm{m})$ were arranged in two pairs positioned linearly along the shank of the ceramic backbone probe (Quanteon; Nicholasville, KY). The members of a pair of recording sites were separated by 30 $\mu \mathrm{m}$ and pairs were separated along the vertical axis by $100 \mu \mathrm{m}$ (Fig. 1). 
Insert Figure 1 about here

An exclusion layer of $m$-(1,3)-phenylenediamine (mPD) was electroplated onto the surface of each recording site by applying a constant voltage of $0.85 \mathrm{~V}$ versus an $\mathrm{Ag} / \mathrm{AgCl}$ reference electrode (Bioanalytical Systems; West Lafayette, IN) for 5 min to prevent sensing of electroactive interferents such as ascorbic acid (AA) and catecholamines. After allowing 24 hours for sites to dry, the top pair of electrodes, further named choline sensors, were coated with a solution of choline oxidase (Sigma-Aldrich; St. Louis, MO) cross-linked with a BSA and glutaraldehyde mixture by manual application of microdroplets using a 1- $\mu$ l Hamilton syringe. The lower pair of sites were coated with only the BSA and glutaraldehyde mixture to identify currents unrelated to the presence of choline (hence named "sentinels"). Following a 48-hr minimum incubation period to allow for optimal adherence of the enzyme layer, recording sites were calibrated to determine the sensitivity for choline, selectivity for choline versus interferents, and limit of detection of choline. Calibrations were performed using a FAST-16 electrochemical system (Quanteon) to apply a constant voltage of $0.7 \mathrm{~V}$ versus an $\mathrm{Ag} / \mathrm{AgCl}$ reference electrode in a heated bath of 40 $\mathrm{ml} 0.05 \mathrm{M}$ PBS. After a 30 minute baseline, $20 \mathrm{mM} \mathrm{AA}$ (interferent), $20 \mathrm{mM}$ choline (analyte), and $2 \mathrm{mM}$ dopamine were added to the bath to generate the following concentrations: $250 \mu \mathrm{M}$ $\mathrm{AA}, 20,40$, and $60 \mu \mathrm{M}$ choline, and $2 \mu \mathrm{M}$ dopamine. Changes in amperometric current recorded at the individual electrode sites following the addition of each solution were used to calculate site sensitivity, selectivity, and limit of detection. In order to qualify for use in in vivo experiments, choline sensors were required to have a sensitivity of $>5 \mathrm{pA} / \mu \mathrm{M}$, choline:AA selectivity ratio $>80: 1$, and a limit of detection $<0.9 \mu \mathrm{M}$ choline.

Probes that passed the above calibration criteria were prepared for in vivo experiments. Glass capillaries (1.0 × $0.58 \mathrm{~mm}$, with filament; A-M Systems; Sequim WA) were pulled using a micropipette puller (Model 51210, Stoelting), and the tips were clipped until the inner diameter was approximately $15 \mu \mathrm{m}$. Pipettes were immobilized to the probe surface using clay and wax such that the tip of the pipette was positioned on the mid-line between the upper and lower site pairs, approximately $50 \mu \mathrm{m}$ from the probe surface (Fig. 1e,f). Micropipettes were filled with one of the following solutions immediately prior to surgery: $5 \mathrm{mM}$ choline, $5 \mathrm{mM}$ choline and $10 \mu \mathrm{M}$ $\mathrm{HC}-3,20 \mu \mathrm{g} / \mu \mathrm{L}$ lidocaine $\mathrm{HCl}$, or either 70 or $120 \mathrm{mM} \mathrm{KCl}$. All drug solutions were prepared in DI water. 
In vivo amperometric recordings. Mice were anesthetized using isoflurane gas (4\% induction and $1-2 \%$ maintenance) and mounted in a stereotaxic frame on an isothermal heating pad to maintain a $37^{\circ} \mathrm{C}$ body temperature. Eyes were lubricated with ophthalmic ointment. A craniotomy and durotomy were performed above the right medial frontal cortex at the site $A P=+1.9 \mathrm{~mm}$ and $\mathrm{ML}$ $=-0.5 \mathrm{~mm}$ from bregma, using a bent 27-gauge needle for dura removal. The prepared microelectrode probe was then lowered $2.0 \mathrm{~mm}$ dorsoventrally from the top of the brain, while an $\mathrm{Ag} / \mathrm{AgCl}$ reference electrode was implanted at a remote site in the contralateral hemisphere. Amperometric recordings were achieved using a FAST-16 electrochemical system and digitized at a sampling rate of $10 \mathrm{~Hz}$. Pressure ejections began following a 60-minute baseline period. Choline sensing was accomplished through choline oxidase catalyzation of the conversion of choline into hydrogen peroxide and glycine betaine. The hydrogen peroxide byproduct was oxidized electrochemically via FAST application of $0.7 \mathrm{~V}$ versus the $\mathrm{Ag} / \mathrm{AgCl}$ reference electrode. The resulting current, over background activity, was previously demonstrated to reflect either choline derived from newly released acetylcholine (ACh) and hydrolyzed by endogenous AChE (references above), or choline concentrations resulting from pressure ejections of choline into the recording area. In the latter case, diminishing choline currents were shown to largely reflect clearance by the $\mathrm{CHT}$, as indicated by the attenuation of clearance efficiency following $\mathrm{CHT}$ blockade with HC-3 (Parikh et al., 2013; Parikh and Sarter, 2006; Parikh et al., 2006).

Choline clearance. We determined the impact of the Val89 variant on CHT-mediated clearance of choline pressure-ejected into the recording field. Micropipettes were filled with a $5 \mathrm{mM}$ choline solution and pressure ejections of 10-35 nL (corresponding to a recorded amplitude of 10-35 $\mu \mathrm{M}$ choline) were administered at least one minute apart to limit inter-trial interference on choline clearance. The first 3 current traces within the 10-35 $\mu \mathrm{M}$ range were used for analysis.

In separate mice, exogenous choline clearance in the presence of HC-3 (Sigma-Aldrich) was determined to test the relative contribution of heterozygous and homozygous CHT Val89 expression, as compared to the expression of the $\mathrm{CHT}$ Ile89, to choline clearance. Micropipettes were filled with a cocktail of $5 \mathrm{mM}$ choline and $10 \mu \mathrm{M} \mathrm{HC}-3$. Pressure ejections were separated by a minimum of two minutes, and, as with the previous experiment, only the first 3 ejection traces with a peak amplitude between 10-35 $\mu \mathrm{M}$ were used in subsequent analyses to avoid aggregating effects of serial HC-3 ejections. Clearance data from previous sessions in which only $5 \mathrm{mM}$ choline was ejected were used as a baseline measure of comparison for all analyses regarding the inhibitory effects of $\mathrm{HC}-3$. 
In a third experiment, to quantify total voltage-dependent choline clearance, exogenous choline clearance was tested before and after administrating the voltage-gated sodium channel blocker, lidocaine $\mathrm{HCl}$ (Hospira Inc.; Lake Forest, IL). In addition to inhibiting neuronal activity (Tehovnik and Sommer, 1997; Malpeli and Schiller, 1979) that supports CHT surface trafficking (Ferguson et al., 2003), lidocaine-induced increases in sodium concentrations (Onizuka et al., 2008) and intracellular proton levels disrupt CHT function (Chu and Lee, 1994; Iwamoto et al., 2006). For this experiment, two micropipettes, one filled with $5 \mathrm{mM}$ choline and the other filled with $20 \mu \mathrm{g} / \mu \mathrm{L}$ lidocaine $\mathrm{HCl}$, were immobilized to the probe. Recording sessions consisted of 2 baseline pressure ejections of $5 \mathrm{mM}$ choline, followed by a single $0.5 \mu \mathrm{L}$ infusion of lidocaine $\mathrm{HCl}$ given over three minutes, a 2-minute rest period for drug diffusion, and finally, a second series of 2 postlidocaine choline ejections (Malpeli and Schiller, 1979; see timeline in Fig. 5c). These parameters were also used in an experiment designed to verify the efficacy of lidocaine by measuring effects on depolarization-induced release of endogenous ACh. In one male WT mouse, pre- and postlidocaine pressure ejections of $\mathrm{KCl}(70 \mathrm{mM}$; 40-60 nL) were used to generate ACh release events.

ACh release capacity following repeated depolarization. A final amperometric experiment determined the impact of the Val89 variant on ACh release following repeated depolarization. Repeated series of pressure ejections of potassium chloride $(\mathrm{KCl} ; 120 \mathrm{mM}$; 30-40 nL per pressure ejection) were used to induce low-frequency, behaviorally-relevant episodes of ACh release. Choline currents following $\mathrm{KCl}$-induced depolarization have previously been shown to reflect the hydrolysis of newly released ACh (Parikh and Sarter, 2006; Parikh et al., 2004; see Results for further justification and additional references). Each depolarization series consisted of 5 evenly distributed $\mathrm{KCl}$ ejections delivered over $2 \mathrm{~min}$, with an ejection delivered every $24 \mathrm{~s}$. Two depolarization series, separated by 15-20 min, were followed by a 5- and a 10-min pause, after which a single $\mathrm{KCl}$-induced $\mathrm{ACh}$ release was measured (see timeline in Fig. 5a).

Analysis of choline currents. Choline currents were calculated by subtracting the background current recorded on sentinel sites from the choline-specific current recorded on choline sensors. Current was then converted to choline concentration based on calibration data. Choline clearance capacity was analyzed by calculating the slope of current decline from $40 \%$ to $80 \%$ of the peak choline concentration (Slope $40-80$ ). Slope $40-80$ was previously shown to be maximally sensitive to $\mathrm{CHT}$ inhibition by $\mathrm{HC}-3$, indicating that this measure primarily reflects choline clearance via $\mathrm{CHT}$ mediated transport (Parikh and Sarter, 2006). From the recordings from each mouse, we analyzed the decay slopes of the first three traces which exhibited peak amplitudes between 10 and $35 \mu \mathrm{M}$. To foster visual comparisons between genotype- and trial-based slope differences, 
and to minimize confounds resulting from minor variations in the amount of choline pressure ejected into the recording region, concentration values were normalized to the peak concentration amplitude. To do this, concentration values were divided by the peak concentration to express each value as a proportion of the peak amplitude. Normalized concentration values were not used in any statistical analyses. Choline currents obtained from experiments assessing $\mathrm{KCl}$-induced depolarization were not normalized because the absolute amplitude of currents reflecting ACh release events were the primary measure of the release capacity of cholinergic terminals.

\section{Determination of synaptosomal CHT density}

Synaptosome preparation. Urethane-anesthetized mice were decapitated and frontal cortices were dissected on ice immediately. Isolated tissues were homogenized in ice-cold $0.32 \mathrm{M}$ sucrose and centrifuged at $1000 \times \mathrm{g}$ for $4 \mathrm{~min}$ at $4^{\circ} \mathrm{C}$ to remove cellular debris. Next, the supernatant was centrifuged at $12,500 \times \mathrm{g}$ for $15 \mathrm{~min}$ to yield a crude synaptosomal pellet. Pellets were stored at $80^{\circ} \mathrm{C}$ until fractioned.

Isolation and quantification of plasma membrane-enriched fractions. In addition to the determination of CHT density in total synaptosomal lysates, subcellular fractionation was conducted to isolate CHTs in a plasma membrane-enriched fraction (Parikh et al., 2013; Ferguson et al., 2003; Parikh et al., 2006). Briefly, the synaptosomal pellet was lysed in $5 \mathrm{~mm}$ HEPES$\mathrm{NaOH}, \mathrm{pH} 7.4$, containing a cocktail of protease inhibitors $(1.0 \mu \mathrm{g} / \mathrm{ml}$ leupeptin, $1.0 \mu \mathrm{g} / \mathrm{ml}$ aprotinin, $1.0 \mu \mathrm{g} / \mathrm{ml}$ pepstatin, and $250 \mu \mathrm{g} / \mathrm{ml}$ phenylmethylsulfonyl fluoride). The fraction was collected by spinning the lysate at $15,000 \times g$ for $20 \mathrm{~min}$. Proteins were extracted from each fraction with $5 \mathrm{~mm}$ HEPES-KOH ( $\mathrm{pH}$ 7.2) solution containing 1\% SDS, $1 \mathrm{~mm}$ EDTA, $1 \mathrm{~mm}$ EGTA, and protease inhibitor cocktail. Protein concentrations were determined by using a modified Lowry Protein Assay (Pierce). Equal quantities $(25 \mu \mathrm{g})$ of protein from each fraction were subjected to immunoblot analysis. Proteins were separated on 4-15\% Tris $\mathrm{HCl}$ polyacrylamide gels and transferred to PVDF membranes. Immunodetection of $\mathrm{CHT}$ bands was accomplished by incubating the membraned overnight with 1:2000 diluted rabbit anti-CHT polyclonal antibody (ABN458; Millipore). The membranes were then exposed to peroxidase-conjugated anti-rabbit secondary antibody and SuperSignal West Femto Maximum Sensitivity Substrate (ThermoFisher Scientific). The resulting chemiluminescent signal was acquired with a Chemidoc Touch Imaging System (Bio-Rad). Densitometric analysis of CHT-immunoreactive bands was performed by calculating the integrated pixel densities using NIH ImageJ software. The membranes were stripped for the detection of $\beta$-actin in all samples that served as a control to accommodate any differences in the sample loading during gel electrophoresis. CHT densities were normalized to 
the levels of $\beta$-actin-immunoreactive bands for each sample analyzed. Total synaptosomal CHT density was determined in frontal cortical tissue from 6 mice (3 females) per genotype. CHT density in the plasma membrane-enriched fraction was measured in tissues from 10 mice (5 females) per genotype.

Structural modeling of the mSLC5A7 WT and I89V substitution. To identify a suitable structural template for mouse CHT we used Hidden Markov model profiles (HMM) as a descriptor for the transporter's amino acid sequence. The HMM profile obtained after a three-iteration sequence scanning performed using UniRef30 sequence database was subsequently scanned against the HMMs of the sequences corresponding to each of the Protein Data Bank (PDB) X-ray structures (pdb70 database) as per standard procedure in HHpred server (Hildebrand et al., 2009; Zimmermann et al., 2018). This method has been shown to increase the successful identification of templates by $30 \%$, especially for distantly related sequences. The Vibrio parahaemolyticus sodium/sugar symporter vSGLT (PDB id: 3DH4) (Faham et al., 2008) had the highest coverage (422 residues), the highest sequence identity (19\%) and better correspondence between secondary structural elements and, as consequence, was selected as template during the structural modelling procedure. To further determine the architectural similarity of $\mathrm{CHT}$ and vSGLT we analyzed their hydrophobicity profiles. The hydrophobicity profiles for these proteins were constructed and aligned using AlignMe server (Stamm et al., 2014, 2013; Khafizov et al., 2010) and applying the Hessa et al. (2005) hydrophobicity scale and a 13-residue long window.

The initial sequence alignment between vSGLT and CHT obtained from HHpred was modified to align the first transmembrane helix (TM1) of vSGLT with that predicted in CHT by Topcons server (Tsirigos et al., 2015). The resulted alignment was then refined in an iterative process that used conservation scores obtained with Consurf server (Ashkenazy et al., 2016) as a guide. This procedure positions the most conserved residues packing towards the core of the protein and removes gaps within secondary structural elements when needed. The final alignment was used during the modelling production run where 2000 modelling iterations were performed with MODELLER (Webb and Sali, 2016). The model with the highest MODELLER probability distribution function score (molPDF), best ProQM score (Ray et al., 2010) and Procheck analysis (Laskowski et al., 1993) was selected as the final WT CHT model. A similar procedure was subsequently used to obtain the structural model of CHT Val89.

Experimental design and statistical analysis 
Choline clearance capacity was assessed using the rate $(\mu \mathrm{M} / \mathrm{s})$ of choline concentration decline from 40 percent to 80 percent of the choline transient peak (Slope $40-80$ ). An initial ANOVA of the effects of genotype was conducted to demonstrate that pressure ejections of choline produced similar peak amplitudes in the three strains. A two-factor mixed model ANOVA was used to determine genotype differences, and the effects of repeated (3) pressure ejections of choline, on choline clearance rate for choline-only ejection experiments. Two-way ANOVAs were used to test the effect of $\mathrm{CHT}$ inhibitor, $\mathrm{HC}-3$, and lidocaine administration, on choline clearance rates (Slope $40-80)$.

The effects of repeated depolarizations on evoked ACh release were analyzed using one-way and mixed model ANOVAs (see Fig. 5a for experimental manipulations and timeline). In each case, results from Shapiro-Wilks tests of Normality and Levene's equality of variance supported the use of parametric analyses. Effects of the very first pressure ejection of potassium on absolute peak amplitudes of choline currents in the three strains were analyzed using one-way ANOVA. The effects of subsequent $\mathrm{KCl}$ ejections were expressed as a ratio of the effects of the first ejection. The effects of genotype on the peak amplitudes of currents evoked by subsequent depolarizations ( $2^{\text {nd }}$ to $5^{\text {th }}$ depolarization) were analyzed first by mixed model ANOVAs on the effects of genotype and $\mathrm{KCl}$ series (first versus second) separately for the $2^{\text {nd }}$ and $5^{\text {th }} \mathrm{KCl}$ pressure ejection (with alpha set at 0.05/2). Based on the absence of significant effects from these two analyses, individual means over the two $\mathrm{KCl}$ series were analyzed for the effects of genotype and $\mathrm{KCl}$ ejection number $\left(2^{\text {nd }}\right.$ versus $\left.5^{\text {th }}\right)$. Peak amplitudes of currents recorded during the recovery tests, 5 and 10 min after the depolarization series, were expressed relative to the peak amplitudes of the first $\mathrm{KCl}$-induced choline current of that series. Effects of genotype and series were analyzed using mixed model ANOVA, once again supported by the results of Shapiro-Wilk and Levene's equality tests. CHT densities in total synaptosomal lysates and plasma membraneenriched fractions were compared between the genotypes using one-way ANOVA.

For parametric mixed-model ANOVAs, in case of violation of the sphericity assumption, HuynhFeldt-corrected $\mathrm{F}$ values, along with uncorrected degrees of freedom, are given. Tests used for post hoc multiple comparisons are identified in figure legends. Data graphs depict individual values, means and 95\% Confidence Intervals (Cl). Statistical analyses were performed using SPSS for Windows (version 17.0; SPSS) and GraphPad Prism Version 8.2.1. with alpha set to 0.05. Exact $P$ values were reported (Greenwald et al., 1996; Sarter and Fritschy, 2008; Michel et al., 2020). For major results derived from parametric tests, effect sizes (Cohen's $d$ ) were indicated (Cohen, 1988). 


\section{Results}

Impact of Val89 on CHT-mediated choline clearance

Reduced clearance of exogenous choline. Together with the experiments assessing choline clearance in the presence of the $\mathrm{CHT}$ blocker $\mathrm{HC}-3$ and following lidocaine-induced suppression of CHT function and, more broadly, neuronal activity (further below), these experiments were designed to determine, in vivo, the capacity of the $\mathrm{CHT}$ in the cortex of $\mathrm{CHT} \mathrm{I/I,} \mathrm{I/V} \mathrm{and} \mathrm{V/V}$ genotypes (see Figure 1 for an illustration of the measurement scheme and the placement of the electrode/glass capillary in the brain). The first series of experiments assessed the clearance of exogenous choline by focusing on the Slope $_{40-80}$ that was previously demonstrated to reflect primarily CHT-mediated transport (see Methods for details and references). Following pressure

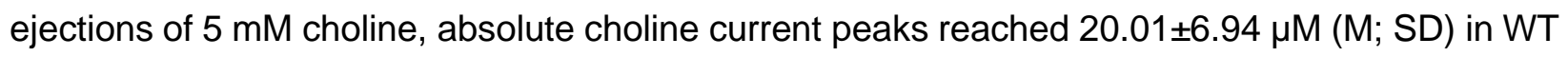
mice, 17.70 $4.43 \mu \mathrm{M}$ in CHT I/V mice, and 22.48 \pm 8.45 $\mu \mathrm{M}$ in CHT V/V mice (genotype: $\mathrm{F}(2,36)=1.58, P=0.22$; data not shown).

Insert Figure 2 about here

A mixed-model ANOVA on the effects of genotype and repeated pressure ejections on Slope $40-80$ indicated a main effect of genotype $(\mathrm{F}(2,36)=6.91, P=0.01$, Cohen's $d=2.35)$ and neither an effect of repeated pressure ejections of choline nor a significant interaction between the two factors (main effect: $F(2,36)=0.22$; interaction: $F(4,36)=0.62$; both $P>0.41$ ). Multiple comparisons (LSD) indicated significantly slower decay rates in $\mathrm{CHT} \mathrm{I/V} \mathrm{and} \mathrm{CHT} \mathrm{V/V} \mathrm{mice} \mathrm{when} \mathrm{compared} \mathrm{with} \mathrm{WT}$ mice $(P<0.012)$, but no gene dosage effect $(P=0.83)$. Figure $2 \mathrm{~b}$ illustrates that decay rates in $\mathrm{CHT}$ Val89 mice on average were reduced by over 77\% (CHT I/V) and 83\% (CHT V/V) relative to WT mice. The low residual decay rates in $\mathrm{CHT} \mathrm{I/V}\left(25^{\text {th }}\right.$ percentile: $\left.0.7 \mu \mathrm{M} / \mathrm{s} ; 75^{\text {th }}: 1.6 \mu \mathrm{M} / \mathrm{s}\right)$ may have prevented the demonstration of even lower decay rates in CHT V/V mice. This issue was further addressed by the next two experiments.

Impact of hemicholinium-3. We co-pressure ejected choline and the competitive CHT inhibitor $\mathrm{HC}-3$ to demonstrate that the choline clearance measure used above (Slope $40-80$ ) indeed reflects primarily CHT-mediated choline clearance (Parikh and Sarter, 2006), and to explore whether CHT-mediated choline transport can be further reduced in Val89 mice by pharmacological blocking of the transporter (see Materials and Methods for details about the ejection parameters). 
Fig. 3a illustrates the marked slowing of choline clearance in the presence of HC-3 in WT CHT I/I mice, contrasting with the absence of a change in the slopes of the decay curves in CHT I/V (Fig. 3b) and CHTV/V (Fig. 3c) mice. The resulting Slope $40-80$ values are shown in Fig. 3d.

Insert Figure 3 about here

ANOVA of the effects of genotype and HC-3 on choline clearance (Slope $40-80$ ) indicated main effects and a significant interaction between the two factors (genotype: $F(2,167)=83.46$, $P<0.0001, d=1.9$; HC-3: $\mathrm{F}(1,167)=74.99, P<0.0001, d=1.3$; interaction: $\mathrm{F}(2,167)=57.11, P<$ $0.0001, d=1.5)$. Post hoc multiple comparisons indicated a HC-3-induced significant decline in the clearance rate in WT mice $(P<0.0001)$, but not in CHT I/V or CHT V/V mice (both $P>0.81$; Fig. $3 d)$. Indeed, choline clearance rates did not differ significantly between the genotypes in the presence of HC-3 (all P>0.06). A final post hoc comparison between absolute peak choline currents recorded following pressure ejections of solutions including and not including $\mathrm{HC}-3$ $(\mathrm{t}(25)=0.09, P=0.93$; data not shown) confirmed that effects on choline clearance were not confounded by differences in the volume and constitution of the ejection solution.

Together, the findings from the experiments on the effects of $\mathrm{HC}-3$ confirm that the measure of choline clearance $\left(\right.$ Slope $_{40-80}$ ) reflects CHT-mediated clearance, and they indicate that the low clearance rates in both variants were not measurably reduced by HC-3-induced blockade. As the affinity of $\mathrm{HC}-3$, in the absence of extracellular choline, is unaffected by the Val89 variant (Okuda et al., 2002), the unexpectedly large impact of both variants on choline clearance, indicated by residual clearance rates below $1 \mu \mathrm{M} / \mathrm{s}$, may have limited the demonstration of any further inhibition by HC-3. However, as the CHT supports vital functions (Ferguson et al., 2004) and thus was expected to remain functional in Val89 mice, we conducted an experiment designed to demonstrate such residual functionality.

Inactivation by lidocaine. Inactivation of neuronal activity and suspension of CHT activity by lidocaine (Tehovnik and Sommer, 1997; Malpeli and Schiller, 1979; Iwamoto et al., 2006; Onizuka et al., 2008) was implemented to determine whether voltage-dependent choline clearance can be detected in CHT Val89 mice. In the presence of lidocaine, residual choline clearance rates are thought to reflect diffusion (Cass et al., 1993) and, potentially, choline uptake via low-affinity, electrogenic transporters other than CHT (Michel et al., 2006). Therefore, lidocaine was expected to suppress the already low choline clearance rates in Val89 mice. 
Insert Figure 4 about here

We confirmed the efficacy of lidocaine to suspend neuronal depolarization in the recording area by measuring $\mathrm{K}^{+}$-evoked, depolarization-induced $\mathrm{ACh}$ release in one WT mouse. Three traces each prior and $\sim 2-4 \mathrm{~min}$ after the lidocaine infusions $(0.5 \mu \mathrm{L}$ over $3 \mathrm{~min})$ are illustrated in Fig. $4 \mathrm{a}$. Peak amplitudes reached about $10 \mu \mathrm{M}$ prior to inactivation and $2 \mu \mathrm{M}$ following lidocaine (Fig. $4 \mathrm{~b}$ ), consistent with prior results showing less than complete inactivation following intracranial infusions of relatively small volumes of lidocaine (Tehovnik and Sommer, 1997).

Choline clearance rates were assessed following the timeline of choline pressure ejections and lidocaine infusions illustrated in Fig. 4c. First, we compared choline clearance rates (Slope $40-80)$ measured prior to lidocaine infusions with those measured in our initial experiment (Fig. 2b). This analysis reproduced the main effect of genotype $(\mathrm{F}(2,45)=12.23, P<0.001)$, reflecting that $\mathrm{CHT} \mathrm{I} / \mathrm{I}$ clearance rates were higher than in CHT I/V $(P=0.0004)$ or $\mathrm{CHT}$ V/V mice $(P<0.0001)$. Furthermore, choline clearance rates across the three strains did not differ between the two experiments $(F(1,45)=1.26, P=0.27)$.

As illustrated in Figs. 4d-g, lidocaine-induced inactivation reduced choline clearance in all three genotypes (main effect of lidocaine: $F(1,27)=104.40, P<0.0001, d=3.9$ ), with relatively greater effects seen in WT than in Val89 mice (main effect of genotype: $F(2,27)=21.12, P<0.0001, d=2.5$; interaction: $F(2,27)=13.40, P<0.0001, d=2.0)$. Moreover, these results are consistent with an absence of genotype-related differences in clearance rates when transport by CHT and other electrogenic transporters are suppressed (all $P>0.10$; Fig. $4 \mathrm{~g}$ ).

Attenuated ACh release capacity following repeated depolarization in vivo.

The results described above indicate a highly significant reduction in choline clearance in CHT Val89 mice when compared with mice expressing the WT CHT lle89 transporter. Such a reduction is expected to impact the capacity of cholinergic neurons to synthesize and release ACh, particularly when cholinergic activity is relatively high and presynaptic "reloading" of newly synthesized ACh is taxed. Basal forebrain cholinergic neurons exhibit highly diverse firing patterns, with firing bursts of subpopulations of these neurons reaching $>80 \mathrm{~Hz}$ (e.g., Laszlovszky et al., 2020; Manns et al., 2000; Duque et al., 2000). However, given our focus on cholinergic activity during attention, we employed a markedly lower frequency and degree of cholinergic 
taxation to foster an interpretation of results in the context of the inattentive phenotype in humans expressing the Val89 variant. Attention tasks such as those used in humans and rodents to reveal attentional impairments typically consist of trial frequencies of $\sim 1$ to $0.1 \mathrm{~Hz}$ (e.g., Berry et al., 2014; Demeter et al., 2008). In such tasks, ACh release events occur during successful cue detection (Gritton et al., 2016). We tested ACh release capacity in CHT Val89 mice following a relatively small number of potassium-induced depolarizations, delivered at a relatively low rate (see Methods; Fig. 5a). ACh release capacity was assessed 5 and $10 \mathrm{~min}$ after such depolarization trains (Fig. 5a), mirroring recovery periods that previously revealed ACh release deficiencies in heterozygous CHT knockout mice (Parikh et al., 2013).

Insert Figure 5 about here

The very first pressure ejection of $\mathrm{KCl}$ produced statistically similar choline current peaks in the three genotypes $(F(2,12)=0.79, P=0.48 ; \mathrm{M}$, SEM ( $\mu \mathrm{M}$ choline): WT: $11.65 \pm 2.06$; CHT I/V: 10.47 \pm 1.55 ; CHT V/V: 8.15 \pm 2.24 ; not shown). The peak amplitudes of the choline currents evoked by the subsequent $2^{\text {nd }}, 3^{\text {rd }}, 4^{\text {th }}$ and $5^{\text {th }}$ pressure ejections of $\mathrm{KCl}$ were expressed as percent of the peaks of the first ejection from the respective depolarization series. Irrespective of genotype and series, the repeated depolarizations during either series appeared to yield increasingly smaller peak amplitudes. Figs. $5 b$ and $c$ show the relative peak amplitudes evoked by the $2^{\text {nd }}$ and $5^{\text {th }}$ ejection of both series. There were no effects of genotype or $\mathrm{KCl}$ series $\left(1^{\text {st }}\right.$ versus $2^{\text {nd }}$; see Fig. 5a) on peak amplitudes evoked by the $2^{\text {nd }}$ or $5^{\text {th }} \mathrm{KCl}$ ejections (main effects of genotype, series and interactions, analyzed separately for the $2^{\text {nd }}$ and $5^{\text {th }}$ ejection, with alpha $=0.05 / 2$ : all $F<2.53$, all $P>0.12$ ). Therefore, the mean relative peak amplitude for each mouse was used to compare the effects of the $2^{\text {nd }}$ and $5^{\text {th }}$ ejection. This analysis indicated that irrespective of genotype, peak amplitudes were markedly reduced following the $5^{\text {th }}$ ejection (main effect of ejection: $F(1,12)=88.89, P<0.001$; Cohen's $d=5.08$; overall $M$, SEM: $2^{\text {nd }}$ ejection: $81.54 \pm 2.56 \% ; 5^{\text {th }}$ : $56.03 \pm 2.11 \%$; Figs $5 \mathrm{~b}, \mathrm{c}$ ). These findings indicate the efficiency of the relatively low-frequency depolarization trains with $\mathrm{KCl}$ to reveal the limits of cholinergic terminals to synthesize and release ACh.

Five minutes following the first and 10 minutes following the second $\mathrm{KCl}$-induced depolarization series, one additional depolarization was administered to test the "reloading" capacity of cholinergic neurons in the 3 genotypes. Representative traces of absolute $\mathrm{KCl}$-induced currents 
(peaks matching the means of the genotype) are shown in Fig. $5 d$ and suggested reduced amplitudes in $\mathrm{CHT} \mathrm{I/V} \mathrm{and} \mathrm{CHT} \mathrm{V/V} \mathrm{mice,} \mathrm{relative} \mathrm{to} \mathrm{CHT} \mathrm{I/I} \mathrm{mice,} \mathrm{at} \mathrm{both} \mathrm{time} \mathrm{points.} \mathrm{To} \mathrm{indicate}$ the degree of synthesis and release recovery, peak amplitudes of choline currents were expressed as a ratio to the peak amplitudes of currents evoked by the first depolarization from the respective series (Fig. 5e and f). Irrespective of genotype, relative peak amplitudes recorded after the 10-min pause were higher than those recorded after the 5-min pause (main effect: $F(1,12)=6.11, P=0.03$; Cohen's $d: 1.42$; M, SEM: 5 min: 80.86 $\pm 5.18 \%$; $10 \mathrm{~min}: 102.38 \pm 5.69 \%$; Fig. 5e). Moreover, a main effect of genotype $(F(2,12)=7.16, P=0.009$; Cohen's $d=2.18$; Fig. 5f) reflected a relatively greater recovery of $\mathrm{ACh}$ release in $\mathrm{CHT} \mathrm{I/I} \mathrm{mice} \mathrm{than} \mathrm{either} \mathrm{of} \mathrm{the} \mathrm{CHT}$ Val89expressing mice (no difference between $\mathrm{CHT} I / \mathrm{V}$ and $\mathrm{CHT} V / \mathrm{V}$; genotype $x$ series: $\mathrm{F}(2,12)=0.56$, $P=0.59, d=0.61$; multiple comparisons, using LSD, are shown in Fig. 5f). Taken together, this experiment indicated the efficiency of the depolarization series to reduce ACh output and an attenuated capacity of cholinergic neurons of $\mathrm{CHT}$ I/V and CHT V/V mice to regain baseline ACh release levels after relatively long, 5- and 10-min pauses.

\section{CHT densities do not differ between genotypes}

Because of our overall focus on the role of fronto-cortical cholinergic signaling in attention (e.g., Howe et al., 2017; Gritton et al., 2016) and that CHT I/V humans fail to activate right frontal cortex during attention (Berry et al., 2015), frontal cortices were harvested for the analysis of CHT densities in total synaptosomal lysates and synaptosomal plasma membrane-enriched fractions. We previously demonstrated that $\mathrm{CHT}$ density in the latter relatively precisely predicts choline clearance capacity (Koshy Cherian et al., 2019; Parikh et al., 2013; Apparsundaram et al., 2005; Ferguson et al., 2003). As illustrated in Figure 6, CHT densities in neither total synaptosomal lysates nor plasma membrane-enriched fractions differed by genotype (both $F<0.58$, both $P>0.56)$. These findings are consistent with the view that attenuated choline clearance and ACh release following repeated depolarizations likely reflects a conformational modification of the protein induced by the Val89 variant that impacts transporter function rather than translation, stability or surface trafficking of CHT protein.

Insert Figure 6 about here 


\section{Structural modeling of WT mouse CHT and the CHT Val89 variant}

To gain insights into the structural underpinnings of the effect of the $189 \mathrm{~V}$ substitution on the CHT transport mechanism, we pursued a molecular modelling approach for WT mCHT and the Val89 variant. Our approach involved two key steps: identifying a suitable template and determining a high-quality sequence alignment between the template and query used during the production run. The use of hidden Markov model (HMM)-based profiles in fold-recognition algorithms, such as implemented in HHpred, allows for detecting distantly related homolog sequences. This approach identified the Vibrio parahaemolyticus sodium/sugar symporter (vSGLT, PDB id: 3DH4) (Faham et al., 2008) as the best template when compared with other SLC5 family members. The initial alignment of vSGLT and CHT cover $80 \%$ of the sequences with a sequence identity of $19 \%$. Despite relatively low sequence similarity, the hydrophobicity profiles of the two transporters, used as indicators for proteins that share the same fold (Lolkema and Slotboom, 1998; Sarkar and Kellogg, 2010), showed visibly similar widths and distribution of hydrophobicity peaks, indicating that both proteins have a similar fold. It is noteworthy that TM14 in vSGLT has no counterpart in mouse (or human) CHT, which is predicted to have 13 transmembrane helices (Fig. 7a,b), extracellular N- and cytoplasmic C-termini (Fig. 7d).

Insert Figure 7 and 8 about here

The initial alignment was refined using an iterative procedure in which the gaps within secondary structural elements are removed, and the conservation scores from Consurf were used as a guide to position highly conserved residues within the core of the protein (Ashkenazy et al., 2016). The refined sequence alignment shows an overall correspondence between secondary structural elements, except in three of the loops connecting transmembrane helices. This matching was particularly striking for the first 13 TM helices (Fig. 7b). The broad sequence coverage between $\mathrm{mCHT}$ and vSGLT, similarity of the hydrophobicity profiles and matching between the TM helices, further substantiate the view that these two proteins share a common fold. The analysis of the stereochemistry for our model of $\mathrm{CHT}$ shows only one residue, located in a loop, in the disallowed region of the Ramachandran plot obtained with PROCHECK (see Methods). In addition to the excellent stereochemistry, the model has a ProQM score averaged by the number of residues 
(global ProQM score) of 0.67 , comparable to that of the template (0.7), indicating the good quality of the model obtained.

Our work indicates that CHT has a similar global architecture as that of vSGLT (Fig. 7c,d). mCHT was modelled as a dimer, similar to the template, where transmembrane helices TM12 and TM13 constitute the dimerization interface with highly conserved residues taking part in the dimerization interacting network (Figs. 7c,d and 8a,b), supporting the possibility that mouse and human CHT assemble as a dimer. Each of the protomers has an inverted repeat topology, in which TMs 2-6 and TMs 7-11 constitute repeat units 1 and 2 (RU1, RU2) with a similar topology to the core of LeuT (TM1-10) (Faham et al., 2008), and a central cavity formed by TM2, 3, 7, 8 and 13 exposed to the cytoplasm and helices 1,12 and 13 as peripheral.

In our model, we found lle89 to be located in TM3 of CHT, facing the membrane and stabilizing the packing between TM3, TM8 and TM7 by interacting with residues Leu93 (TM3), Tyr238 (TM7) and Leu282 (TM8) (Fig. 8c). This network of interactions is disrupted when lle89 is substituted by Val89 (Fig. 8d), suggesting that the variant may destabilize helical packing in this region. It is worth noting that that these three TMs are predicted to participate in shaping the cavity where choline binds, and thus Val89 may disrupt the exposure of the CHT substrate binding site. In addition, TM3, TM7 and TM8 are part of the "bundle" of the protein, which is believed to move with respect to the scaffold and the membrane plane upon the conformational changes responsible for transitions of the substrate binding site between states open to either extracellular or cytoplasmic spaces (alternating-access mechanism of transport). Destabilization of the fold next to position 89 by the Ile89Val substitution could also affect the ability of the transporter to adopt canonical conformations that the protein needs to reach during a transport cycle.

\section{Discussion}

Previous research established that CHT is an essential mediator of choline clearance capacity supporting ACh synthesis (references in Introduction). The current study aimed to determine the cholinergic impact of the common human CHT coding variant, Val89. We previously demonstrated a robust inattentive phenotype associated with this variant in heterozygous Val89 humans, along with attenuated frontal activation during attentional performance (Berry et al., 2025; Sarter et al., 2016; Berry et al., 2015; Berry et al., 2014). The main results described here indicate a reduction in cortical choline clearance capacity in Val89 mice of approximately $80 \%$. Residual choline transport rates in CHT V/V mice were not significantly lower than in CHT I/V 
mice, consistent with a dominant model for Val89 effects and with heterozygous human Val89 carriers exhibiting the cognitive effects noted above. Immunoblotting indicated that surface expression of the $\mathrm{CHT}$, however, did not differ between the genotypes. Although the initial depolarization-induced release of ACh from cholinergic terminals was similar across all mice, we found that five or ten min following repeated depolarization, the capacity to release ACh was significantly attenuated in Val89 expressing mice.

Results from the depolarization studies (Fig. 4) demonstrated that, in response to the initial depolarization, choline transport by the variant remains sufficient to support ACh release at a level that is comparable to WT mice. However, the impact of attenuated $\mathrm{CHT}$ function on ACh release capacity manifests following repeated depolarizations. Importantly, the paradigm used to assess the "reloading" capacity of cholinergic neurons tested the effects of a relatively small number of depolarizations at a relatively low frequency, mirroring trial-specific ACh release events seen in attentional task-performing rodents ( 5 depolarizations over 2 min followed by a 5 - or 10 -min period for reloading). It is important to note that in attentional task-performing rodents, trial-unrelated levels of ACh release are also elevated and associated with expectation of performance and task engagement per se (e.g., Paolone et al., 2012; Dalley et al., 2001). Therefore, the repeated KClinduced depolarization trains used in the present experimental paradigm were likely to underestimate the impact of the variant on the cholinergic mediation of task performance. Likewise, an even greater impact of the Val89 variant would be expected when cholinergic neurons exhibit burst firing (e.g., Manns et al., 2003), such as is the case for neurons in the parasympathetic nervous system (e.g., Jiman et al., 2020). The impact of the Val89 variant on non-cognitive behaviors, including circadian rhythms (e.g., Paolone et al., 2012), and on autonomic and motor systems, in humans and mice expressing this variant, remains unknown and will require further study.

Our in vivo method indicated a relatively large reduction of CHT-mediated choline transport rates by the variant. Indeed, the unexpectedly low residual transport rates in Val89-expressing mice warranted additional experiments to reveal the functionality of the $\mathrm{CHT}$ variant. The effects of HC3 and lidocaine, while validating our in vivo choline transport measure in terms of a reduction in CHT-mediated transport suggests either a residual, voltage-dependent choline transport capacity of CHT Val89 or a contribution to choline clearance by other electrogenic transporters (e.g., Onizuka et al., 2008). As interactions of choline, sodium, chloride and HC-3 with CHT Val89 have been reported to be unaffected in transfected cells (Okuda et al., 2002), our results are consistent 
with a diminished capacity for the high-affinity choline transport needed to sustain high-demand ACh release.

Our structural models of WT mouse CHT and the Val89 encoding transporter point to a structural importance of lle89 in local packing of substrate transport-critical helices. We show that lle89 is predicted to participate in an interacting network that stabilizes the fold of helices that contribute to the "bundle" domain of the "rocking bundle" model of transport (Forrest and Rudnick, 2009). This network may also contribute to the shaping of the binding site by interacting with TM7 and TM8. Because lle89 is not predicted to contribute to the substrate binding site (see also Okuda et al., 2002), it seems most likely that any impact on choline recognition by Val89 must be indirect. Therefore, we favor a model whereby conformational transitions required to support alternating access of the choline binding site to extracellular and intracellular compartments are compromised. Additionally, our models were well fit to a dimeric structure solved for vSGLT, including TMs position to support the dimeric interface. Such a structure may underlie the robust inhibition of choline clearance we detect in heterozygous Val89 expressing mice, reflecting a dominant-negative mode of action, which has been previously suggested for human diseaseassociated CHT coding variants (Barwick et al., 2012).

Here, we focused on measures of presynaptic cholinergic capacity in the cortex because of the association of the Val89 variant with heightened distractor vulnerability in humans and based on evidence indicating an essential role of cortical cholinergic activity for distractor filtering (references in Introduction). As CHT Val89 mice show no visible signs of paralysis, and under standard housing conditions do not die prematurely, we speculate that there may be a regiondependence to the functional impact of the variant or the contribution of other choline transporters to ACh synthesis, a surmise that can now be pursued with the CHT Val89 mouse model. If confirmed, the impact of the CHT Val89 variant may contrast with the systemic impairments associated with the expression of other loss-of-function $\mathrm{CHT}$ mutations, including the autonomic and motor deficiencies in $\mathrm{CHT}^{+/-}$mice (English et al., 2010; Bazalakova et al., 2007), and the neuromuscular disorders associated with human CHT coding mutations (Wang et al., 2017; Barwick et al., 2012; Bauche et al., 2016; Pardal-Fernandez et al., 2018; Banerjee et al., 2019).

The present findings establish that the Val89 variant, which has previously been linked to attentional impairment in humans (Sarter et al., 2016; Berry et al., 2015; Berry et al., 2014; English et al., 2009), as well as major depression (Hahn et al., 2008), greatly impacts the capacity of cortical cholinergic presynaptic terminals to import choline and to sustain ACh release, even following relatively moderate depolarization rates. As such, the present evidence provides a 
mechanistic framework to interpret the increased distraction vulnerability and frontal cortical activation deficits in Val89-expressing humans. As impairments in cholinergically mediated, attentional-perceptual functions and frontal cortical abnormalities are essential variables in the manifestation of major psychiatric and neurological disorders (Kim et al., 2019; Berry et al., 2017; Lustig and Sarter, 2016; Albin et al., 2018; Sarter et al., 2021; Bohnen et al., 2009; Bohnen and Albin, 2009), further investigation of to the impact of the CHT Val89 variant in humans and $\mathrm{CHT}$ Val89 mice is warranted. We believe that studies examining the relative prevalence of the Val89 variant in patient populations may reveal a significant impact on the risk for development of psychiatric and neurological symptoms, and possibly contribute to risk for cognitive and other behavioral manifestations of neurodegenerative disorders, where cholinergic neurons are selectively vulnerable. 


\section{Figure Legends}

\section{Figure 1}

Diagram of the choline measurement scheme, the glass capillary attached to the electrode and for pressure ejections, and placement of the assembly in the medial frontal cortex. a shows the ceramic backbone with the 4 Platinum (Pt/lr) recording sites, each $333 \mu \mathrm{m}$ long and $15 \mu \mathrm{m}$ wide, organized in two pairs (see text for references) The upper pair was used to measure choline currents (red; see also b) while the lower pairs served as sentinels (yellow; see also c). The choline-sensing scheme is illustrated in abbreviated form in b and c. Choline is oxidized by choline oxidase $(\mathrm{CO})$ that was immobilized onto the upper pair of recording sites. The resulting current, over background activity, was converted to concentration $(\mu \mathrm{M})$. Prior to immobilization of $\mathrm{CO}$, the non-conducting polymer m-(1,3)-phenylenediamine (mPD) was electroplated onto the recording sites to block the transfer of small electroactive organic molecules to the Pt site. Importantly, such mPD films do not block small species such as $\mathrm{H}_{2} \mathrm{O}_{2}$ from reaching the Pt surface (Mitchell, 2004; Huang et al., 1993). The lower pair of recording sites (c) were coated with mPD but not CO and thus served to record the concentration of electroactive interferents, which, despite the mPD barrier, still reached the Pt sites. A top view of the electrode in d shows the Pt recording sites (black arrows), with the upper left Pt site situated underneath a glass capillary (red arrows) used to pressure eject compounds into the recording area (100 $\mu \mathrm{m}$ scale inserted). The entire electrode/glass capillary assembly is shown from the side in e. Note that the Pt recording sites are not visible because of low resolution (1-cm scale vertically inserted on the right) but are located in the very tip of the ceramic backbone (see also the tip of the glass capillary). For the present experiments, the electrode/glass capillary assembly was inserted into the medial frontal cortex of mice. $\mathbf{f}$ shows a coronal section of the frontal cortex (AP: $2.0 \mathrm{~mm} ; 1 \mathrm{~mm}$ scale inserted) and the approximate placement and relative dimensions of the assembly.

\section{Figure 2}

Impact of CHT Val89 on clearance of exogenous choline in mouse frontal cortex. Following insertion of the electrode and glass capillary into the cortex (see Fig. 1) and a 60-min baseline period, repeated pressure ejections of $5 \mathrm{mM}$ choline (10-35 $\mathrm{nL}$ ) were given at 1-2 min intervals. a Choline clearance with concentration normalized to the peak amplitude (currents were recorded at $10 \mathrm{~Hz}$ but for clarity are shown at $2 \mathrm{~Hz}$ ). Choline ejections occurred at time 0 (shown are means and $95 \% \mathrm{Cl}$ ). b Choline clearance rates calculated for the periods of current decay from $40 \%$ to 
$80 \%\left(\right.$ Slope $\left._{40-80}\right)$ of peak amplitudes $(\mu \mathrm{M} / \mathrm{s}$; shown are individual values, means and $95 \% \mathrm{Cl}$; WT, inverted blue triangles, 12 ejections from 4 mice; CHT I/N, green diamonds, 12 ejections from 4 mice; CHT V/V, red triangles, 15 ejections from 5 mice). Clearance rates in both I89V-expressing strains were markedly reduced relative to WT mice (Least Significant Difference (LSD) test; Fig. 5b and subsequent figures depict results from post hoc multiple comparisons; $.{ }^{*},{ }^{* * *},{ }^{* * *}$ : $\mathrm{P}<0.05$. 0.01, 0.001, 0.0001, respectively).

\section{Figure 3}

Impact of the CHT competitive inhibitor HC-3 on choline clearance in WT and CHT Val89 mice. a-c Averaged traces of exogenous choline clearance with and without HC-3. Traces and slopes in the absence of HC-3 were obtained from a separate group of mice (Fig. 2). Choline clearance in the presence of HC-3 was determined from 15 traces in WT $(n=5), 12$ traces in CHT I/V $(n=4)$, and 18 traces in CHT V/V ( $n=6)$, with 3 traces selected from each mouse. Darker colored lines represent choline clearance traces following pressure ejections of $5 \mathrm{mM}$ choline alone, while lighter colors show clearance following ejections of a solution containing $5 \mathrm{mM}$ choline and $10 \mu \mathrm{M}$ $\mathrm{HC}-3$, with each solution ejected at time 0 . Concentrations were normalized to peak amplitude. $\mathbf{d}$ Individual choline clearance rates $(\mu \mathrm{M} / \mathrm{s}$; means and $95 \% \mathrm{Cl}$ ) from Slope $40-80$ following ejections of $5 \mathrm{mM}$ choline only (left) and a $5 \mathrm{mM}$ choline and $10 \mu \mathrm{M} \mathrm{HC}-3$ cocktail (right). Only decay rates recorded in WT mice were significantly slowed by HC-3. There was no difference in slopes between genotypes following $\mathrm{HC}-3$ ejections (LSD test).

\section{Figure 4}

Reduced choline clearance rate following inactivation of neuronal activity and CHT function with lidocaine. An initial experiment, using one WT mouse, was conducted to verify the efficacy of lidocaine $(0.5 \mu \mathrm{L}$ of $20 \mu \mathrm{g} / \mu \mathrm{L}$ infused over a consistent rate of $0.17 \mu \mathrm{L} / \mathrm{min})$ to inactivate the recording area. Prior to lidocaine infusions, $\mathrm{KCl}(70 \mathrm{mM})$ pressure ejections reliably generated ACh release events, peaking at about $10 \mu \mathrm{M}$ (see dark blue traces in a). Two to three min following lidocaine infusions, peak choline currents were markedly reduced (b), yet not completely abolished, as would be expected from the effects of a relatively small volume of lidocaine (Tehovnik and Sommer, 1997). c Timeline of choline pressure ejections and lidocaine infusion used to test choline clearance in the three strains. Following a 60 -min baseline period, two initial pressure ejections of choline $(5 \mathrm{mM})$, separated by $2 \mathrm{~min}$, were followed by the infusion of lidocaine and, 2 min later, by another two pressure ejections of choline. $\mathbf{d , e}$ and $\mathbf{f}$ represent 
averaged (over 8 traces from two mice per genotype) pre- and post-lidocaine currents evoked by exogenous choline in WT (d), CHT I/V (e) and CHT V/V (f) mice. g ANOVA indicated main effects of genotype and lidocaine as well as a significant interaction (Results). LSD multiple comparisons tests indicated significant reductions of choline clearance following inactivation in all 3 genotypes (g; lines and bars indicate means and $95 \% \mathrm{Cl}$ ). The significant interaction between the effects of genotype and lidocaine also reflected that choline clearance rates no longer differed between the genotypes (all $P>0.10$ ).

\section{Figure 5}

Impact of CHT Val89 on ACh release capacity following repeated depolarization. a Schematic illustration of the timeline of $\mathrm{KCl}$ pressure ejections. Following a period of calibration, an initial train of $5 \mathrm{KCl}$ ejections were administered over $3 \mathrm{~min}$ and followed, $5 \mathrm{~min}$ later, by a first release capacity test. After a 15-min pause, a second series of depolarizations was followed, 10 min later, by a second release capacity test. Peak amplitude currents following the first $\mathrm{KCl}$ ejection of either series did not vary by genotype (not shown). b,c show the peak amplitudes of currents evoked by the 2 nd and 5th ejection, respectively, of either series, expressed as a ratio of the amplitudes of the first ejection ( $n=4 \mathrm{I} / \mathrm{I}, 6 \mathrm{I} / \mathrm{V}$, and $5 \mathrm{~V} / \mathrm{V}$ mice; lines and bars in b,c,e,f depict means and 95\% $\mathrm{Cl})$. Compared with the 2 nd depolarization, the 5 th resulted in significantly smaller amplitudes across genotypes and the two series. $\mathbf{d}$ Representative traces of currents evoked at the 5-min and 10-min recovery tests, illustrating attenuated $\mathrm{ACh}$ release in $\mathrm{I} / \mathrm{V}$ and $\mathrm{V} / \mathrm{V}$ mice. e Peak amplitudes of the recovery currents, expressed as the percent of the amplitude of the first depolarization of the respective series, indicated significantly greater recovery after the longer 10min pause compared with peak currents recorded 5-min after the depolarization train (see Results for ANOVA). The analysis of the effects of series and genotype also revealed a main effect of genotype, illustrated in $\mathbf{f}$, that reflected significantly lower peak amplitudes in I/V (12 ejections from $n=6)$ and $V / V(10$ ejections from $n=5)$ mice relative to peak amplitudes in WT mice (8 ejections from $n=4$; LSD test; see f for post hoc multiple comparisons).

\section{Figure 6}

Top: Western blots showing the presence of the $\mathrm{CHT}$ in frontal cortical total synaptosomal lysates (a, top) and synaptosomal plasma-membrane-enriched fractions (b, top; normalized against $\beta$ actin; each lane is based on tissue from one individual; $25 \mu \mathrm{g}$ protein loaded in each well; total and plasma membrane-enriched fractions were derived from separate groups of mice). CHT 
densities in neither total lysates (a) nor plasma membrane-enriched fractions (b) differed between the genotypes (graphs show individual values, means and $95 \% \mathrm{Cl}$ ).

\section{Figure 7}

Structural model of a mouse CHT dimer. a Sequence alignment between mouse and human CHT (SLC5A7) and the template vSGLT used for structural modelling studies. The secondary structure prediction (SSP) averaged over the SLC5A7 profile from HHpred server (Hildebrand et al., 2009) is shown below hSLC5A7 sequence as gray (coil), blue (helix) and red (beta-strand) bars. The transmembrane topology prediction from Topcons server (Tsirigos et al., 2015) is also shown as bars below SSP colored and numbered according to the topology proposed by Faham et al. (2008). The secondary structure and transmembrane helices based on the structure of the template vSGLT are also shown on top of vSGLT sequence, similarly to that of CHT. The region between TM12 and TM13 shaded in gray was not modelled. Residues shown in the model are highlighted according to their properties; neutral in white, aromatic in yellow, polar in green, basic in blue and acidic in red. b Hydrophobicity profiles for mSLC5A7 (red) and vSGLT (black) revealing conserved hydrophobic regions. Residues corresponding to the TM helices in vSGLT or those predicted for mSLC5A7 are indicated as black and red bars at the top of the graph and in the case of mSLC5A7 also as red shading. c,d Final structural model of the dimeric form of mSLC5A7 and the correspondent topology. In both, TM helices are colored according to Faham et al. (2008) and the inverted repeat units are shown as orange and blue triangles.

\section{Figure 8}

Structural model of mouse CHT Val89. a Structural model of mSLC5A7 in dimeric form colored according to the topology. 189 , the sodium ion and substrate are highlighted as orange sticks and purple and light blue spheres, respectively. The position of the substrate and sodium ions where those obtained after structural superimposition of CHT model and vSGLT structure. b Final model of mSLC5A7 where each residue is colored by its conservation score obtained with Consurf server (Ashkenazy et al., 2016). c,d Close-up views of lle89 and Val89 in their corresponding mSLC5A7 structures.Residues interacting with Ile89 are shown as sticks and the distances between sidechains are shown as dashed lines. The helices are colored as in a. 
References

Albin RL, Bohnen NI, Muller M, Dauer WT, Sarter M, Frey KA, Koeppe RA (2018) Regional vesicular acetylcholine transporter distribution in human brain: $A$ [(18) F]fluoroethoxybenzovesamicol positron emission tomography study. J Comp Neurol 526:2884-2897.

Apparsundaram S, Martinez V, Parikh V, Kozak R, Sarter M (2005) Increased capacity and density of choline transporters situated in synaptic membranes of the right medial prefrontal cortex of attentional task-performing rats. J Neurosci 25:3851-3856.

Ashkenazy H, Abadi S, Martz E, Chay O, Mayrose I, Pupko T, Ben-Tal N (2016) ConSurf 2016: an improved methodology to estimate and visualize evolutionary conservation in macromolecules. Nucleic Acids Res 44:W344-350.

Banerjee M, Arutyunov D, Brandwein D, Janetzki-Flatt C, Kolski H, Hume S, Leonard NJ, Watt J, Lacson A, Baradi M, Leslie EM, Cordat E, Caluseriu O (2019) The novel p.Ser263Phe mutation in the human high-affinity choline transporter 1 (CHT1/SLC5A7) causes a lethal form of fetal akinesia syndrome. Hum Mutat 40:1676-1683.

Barwick Katy E, Wright J, Al-Turki S, McEntagart Meriel M, Nair A, Chioza B, Al-Memar A, Modarres H, Reilly Mary M, Dick Katherine J, Ruggiero Alicia M, Blakely Randy D, Hurles Matt E, Crosby Andrew H (2012) Defective presynaptic choline transport underlies hereditary motor neuropathy. American Journal of Human Genetics 91:1103-1107.

Bauche S et al. (2016) Impaired Presynaptic High-Affinity Choline Transporter Causes a Congenital Myasthenic Syndrome with Episodic Apnea. Am J Hum Genet.

Bazalakova MH, Blakely RD (2006) The high-affinity choline transporter: a critical protein for sustaining cholinergic signaling as revealed in studies of genetically altered mice. Handb Exp Pharmacol:525-544.

Bazalakova MH, Wright J, Schneble EJ, McDonald MP, Heilman CJ, Levey AI, Blakely RD (2007) Deficits in acetylcholine homeostasis, receptors and behaviors in choline transporter heterozygous mice. Genes Brain Behav 6:411-424.

Berry AS, Sarter M, Lustig C (2017) Distinct Frontoparietal Networks Underlying Attentional Effort and Cognitive Control. J Cogn Neurosci 29:1212-1225.

Berry AS, Blakely RD, Sarter M, Lustig C (2015) Cholinergic capacity mediates prefrontal engagement during challenges to attention: evidence from imaging genetics. Neuroimage 108:386-395.

Berry AS, Sarter M, Gehring WJ, Lustig C (2025) What happens after perception: a right frontal signature of shifts from perceptual to reflective attention. In preparation.

Berry AS, Demeter E, Sabhapathy S, English BA, Blakely RD, Sarter M, Lustig C (2014) Disposed to distraction: genetic variation in the cholinergic system influences distractibility but not time-on-task effects. J Cogn Neurosci 26:1981-1991.

Bohnen NI, Albin RL (2009) Cholinergic denervation occurs early in Parkinson disease. Neurology 73:256-257.

Bohnen NI, Müller MLTM, Koeppe RA, Studenski SA, Kilbourn MA, Frey KA, Albin RL (2009) History of falls in Parkinson disease is associated with reduced cholinergic activity. Neurology 73:1670-1676.

Burmeister JJ, Moxon K, Gerhardt GA (2000) Ceramic-based multisite microelectrodes for electrochemical recordings. Anal Chem 72:187-192.

Burmeister JJ, Palmer M, Gerhardt GA (2003) Ceramic-based multisite microelectrode array for rapid choline measures in brain tissue. Analytica chimica acta 481:65-74.

Cass WA, Zahniser NR, Flach KA, Gerhardt GA (1993) Clearance of exogenous dopamine in rat dorsal striatum and nucleus accumbens: role of metabolism and effects of locally applied uptake inhibitors. J Neurochem 61:2269-2278. 
Chen N, Sugihara H, Sur M (2015) An acetylcholine-activated microcircuit drives temporal dynamics of cortical activity. Nat Neurosci 18:892-902.

Chu AJ, Lee JM (1994) Lidocaine inhibits choline uptake and phosphatidylcholine biosynthesis in human leukemic monocyte-like U937 cells. Cell Biochem Funct 12:89-98.

Cohen J (1988) Statistical power analysis for the behavioral sciences, 2nd Edition. Hillsdale, N.J.: L. Erlbaum Associates.

Cong L, Ran FA, Cox D, Lin S, Barretto R, Habib N, Hsu PD, Wu X, Jiang W, Marraffini LA, Zhang $F(2013)$ Multiplex genome engineering using CRISPR/Cas systems. Science 339:819823.

Dalley JW, McGaughy J, O'Connell MT, Cardinal RN, Levita L, Robbins TW (2001) Distinct changes in cortical acetylcholine and noradrenaline efflux during contingent and noncontingent performance of a visual attentional task. J Neurosci 21:4908-4914.

Demeter E, Sarter M, Lustig C (2008) Rats and humans paying attention: cross-species task development for translational research. Neuropsychology 22:787-799.

Duque A, Balatoni B, Detari L, Zaborszky L (2000) EEG correlation of the discharge properties of identified neurons in the basal forebrain. J Neurophysiol 84:1627-1635.

English BA, Hahn MK, Gizer IR, Mazei-Robison M, Steele A, Kurnik DM, Stein MA, Waldman ID, Blakely RD (2009) Choline transporter gene variation is associated with attention-deficit hyperactivity disorder. J Neurodev Disord 1:252-263.

English BA, Appalsamy M, Diedrich A, Ruggiero AM, Lund D, Wright J, Keller NR, Louderback KM, Robertson D, Blakely RD (2010) Tachycardia, reduced vagal capacity, and agedependent ventricular dysfunction arising from diminished expression of the presynaptic choline transporter. Am J Physiol Heart Circ Physiol 299:H799-810.

Ennis EA, Blakely RD (2016) Choline on the move: Perspectives on the molecular physiology and pharmacology of the presynaptic choline transporter. Adv Pharmacol 76:175-213.

Faham S, Watanabe A, Besserer GM, Cascio D, Specht A, Hirayama BA, Wright EM, Abramson $J(2008)$ The crystal structure of a sodium galactose transporter reveals mechanistic insights into $\mathrm{Na}+$ /sugar symport. Science 321:810-814.

Ferguson SM, Blakely RD (2004) The choline transporter resurfaces: new roles for synaptic vesicles? Mol Interv 4:22-37.

Ferguson SM, Bazalakova M, Savchenko V, Tapia JC, Wright J, Blakely RD (2004) Lethal impairment of cholinergic neurotransmission in hemicholinium-3-sensitive choline transporter knockout mice. Proc Natl Acad Sci USA 101:8762-8767.

Ferguson SM, Savchenko V, Apparsundaram S, Zwick M, Wright J, Heilman CJ, Yi H, Levey AI, Blakely RD (2003) Vesicular localization and activity-dependent trafficking of presynaptic choline transporters. J Neurosci 23:9697-9709.

Forrest LR, Rudnick G (2009) The rocking bundle: a mechanism for ion-coupled solute flux by symmetrical transporters. Physiology (Bethesda) 24:377-386.

Giuliano C, Parikh V, Ward JR, Chiamulera C, Sarter M (2008) Increases in cholinergic neurotransmission measured by using choline-sensitive microelectrodes: enhanced detection by hydrolysis of acetylcholine on recording sites? Neurochem Int 52:1343-1350.

Gorka AX, Knodt AR, Hariri AR (2015) Basal forebrain moderates the magnitude of taskdependent amygdala functional connectivity. Soc Cogn Affect Neurosci 10:501-507.

Greenwald AG, Gonzalez R, Harris RJ, Guthrie D (1996) Effect sizes and p values: What should be reported and what should be replicated? Psychophysiology 33:175-183.

Gritton HJ, Howe WM, Mallory CS, Hetrick VL, Berke JD, Sarter M (2016) Cortical cholinergic signaling controls the detection of cues. Proc Natl Acad Sci U S A 113:E1089-1097.

Guyenet P, Lefresne P, Rossier J, Beauquan JC, Glowinski J (1973) Inhibition by hemicholinium3 of $[14 \mathrm{C}]$ acetylcholine synthesis and $[3 \mathrm{H}]$ choline high-affinity uptake in rat striatal synaptosomes. Molecular Pharmacology 9:630-639. 
Hahn MK, Blackford JU, Haman K, Mazei-Robison M, English BA, Prasad HC, Steele A, Hazelwood L, Fentress HM, Myers R, Blakely RD, Sanders-Bush E, Shelton R (2008) Multivariate permutation analysis associates multiple polymorphisms with subphenotypes of major depression. Genes Brain Behav 7:487-495.

Hessa T, Kim H, Bihlmaier K, Lundin C, Boekel J, Andersson H, Nilsson I, White SH, von Heijne $\mathrm{G}$ (2005) Recognition of transmembrane helices by the endoplasmic reticulum translocon. Nature 433:377-381.

Hildebrand A, Remmert M, Biegert A, Soding J (2009) Fast and accurate automatic structure prediction with HHpred. Proteins 77 Suppl 9:128-132.

Howe WM, Gritton HJ, Lusk NA, Roberts EA, Hetrick VL, Berke JD, Sarter M (2017) Acetylcholine release in prefrontal cortex promotes gamma oscillations and theta-gamma coupling during cue detection. J Neurosci 37:3215-3230.

Iwamoto H, Blakely RD, De Felice LJ (2006) $\mathrm{Na}+, \mathrm{Cl}-$, and $\mathrm{pH}$ dependence of the human choline transporter (hCHT) in Xenopus oocytes: the proton inactivation hypothesis of hCHT in synaptic vesicles. J Neurosci 26:9851-9859.

Jiman AA, Ratze DC, Welle EJ, Patel PR, Richie JM, Bottorff EC, Seymour JP, Chestek CA, Bruns TM (2020) Multi-channel intraneural vagus nerve recordings with a novel highdensity carbon fiber microelectrode array. Sci Rep 10:15501.

Khafizov K, Staritzbichler R, Stamm M, Forrest LR (2010) A study of the evolution of invertedtopology repeats from LeuT-fold transporters using AlignMe. Biochemistry 49:1070210713.

Kim K, Muller M, Bohnen NI, Sarter M, Lustig C (2019) The cortical cholinergic system contributes to the top-down control of distraction: Evidence from patients with Parkinson's disease. Neuroimage 190:107-117.

Koshy Cherian A, Tronson NC, Parikh V, Kucinski A, Blakely RD, Sarter M (2019) Repetitive mild concussion in subjects with a vulnerable cholinergic system: Lasting cholinergicattentional impairments in CHT+/- mice. Behav Neurosci 133:448-459.

Koshy Cherian A, Kucinski A, Pitchers KK, Yegla B, Parikh V, Kim Y, Valuskova P, Gurnarni S, Lindsley CW, Blakely RD, Sarter M (2017) Unresponsive choline transporter as a trait neuromarker and a causal mediator of bottom-up attentional biases. J Neurosci 37:29472959.

Laskowski RA, MacArthur MW, Moss DS, Thornton JM (1993) PROCHECK: a program to check the stereochemicai quality of protein structures. J Appl Cryst 26:283-291.

Laszlovszky T, Schlingloff D, Hegedus P, Freund TF, Gulyas A, Kepecs A, Hangya B (2020) Distinct synchronization, cortical coupling and behavioral function of two basal forebrain cholinergic neuron types. Nat Neurosci 23:992-1003.

Lolkema JS, Slotboom DJ (1998) Estimation of structural similarity of membrane proteins by hydropathy profile alignment. Mol Membr Biol 15:33-42.

Lustig C, Sarter M (2016) Attention and the cholinergic system: relevance to schizophrenia. Curr Top Behav Neurosci 28:327-362.

Malpeli JG, Schiller PH (1979) A method of reversible inactivation of small regions of brain tissue. J Neurosci Methods 1:143-151.

Manns ID, Alonso A, Jones BE (2000) Discharge profiles of juxtacellularly labeled and immunohistochemically identified GABAergic basal forebrain neurons recorded in association with the electroencephalogram in anesthetized rats. J Neurosci 20:9252-9263.

Manns ID, Alonso A, Jones BE (2003) Rhythmically discharging basal forebrain units comprise cholinergic, GABAergic, and putative glutamatergic cells. J Neurophysiol 89:1057-1066.

McGaughy J, Kaiser T, Sarter M (1996) Behavioral vigilance following infusions of 192 IgGsaporin into the basal forebrain: selectivity of the behavioral impairment and relation to cortical AChE-positive fiber density. Behav Neurosci 110:247-265. 
Mentis MJ, Sunderland T, Lai J, Connolly C, Krasuski J, Levine B, Friz J, Sobti S, Schapiro M, Rapoport SI (2001) Muscarinic versus nicotinic modulation of a visual task. a PET study using drug probes. Neuropsychopharmacology 25:555-564.

Michel MC, Murphy TJ, Motulsky HJ (2020) New Author Guidelines for Displaying Data and Reporting Data Analysis and Statistical Methods in Experimental Biology. Mol Pharmacol 97:49-60.

Michel V, Yuan Z, Ramsubir S, Bakovic M (2006) Choline transport for phospholipid synthesis. Exp Biol Med (Maywood) 231:490-504.

Muir JL, Dunnett SB, Robbins TW, Everitt BJ (1992) Attentional functions of the forebrain cholinergic systems: effects of intraventricular hemicholinium, physostigmine, basal forebrain lesions and intracortical grafts on a multiple-choice serial reaction time task. Exp Brain Res 89:611-622.

Nair J, Klaassen AL, Arato J, Vyssotski AL, Harvey M, Rainer G (2018) Basal forebrain contributes to default mode network regulation. Proc Natl Acad Sci U S A.

Okuda T, Okamura M, Kaitsuka C, Haga T, Gurwitz D (2002) Single nucleotide polymorphism of the human high affinity choline transporter alters transport rate. J Biol Chem 277:4531545322.

Onizuka S, Kasaba T, Tamura R, Takasaki M (2008) Lidocaine increases intracellular sodium concentration through a $\mathrm{Na}+-\mathrm{H}+$ exchanger in an identified Lymnaea neuron. Anesth Analg 106:1465-1472, table of contents.

Paolone G, Lee TM, Sarter M (2012) Time to pay attention: attentional performance time-stamped prefrontal cholinergic activation, diurnality, and performance. J Neurosci 32:12115-12128.

Pardal-Fernandez JM, Carrascosa-Romero MC, Alvarez S, Medina-Monzon MC, Caamano MB, de Cabo C (2018) A new severe mutation in the SLC5A7 gene related to congenital myasthenic syndrome type 20. Neuromuscul Disord 28:881-884.

Parikh V, Sarter M (2006) Cortical choline transporter function measured in vivo using cholinesensitive microelectrodes: clearance of endogenous and exogenous choline and effects of removal of cholinergic terminals. J Neurochem 97:488-503.

Parikh V, Kozak R, Martinez V, Sarter M (2007) Prefrontal acetylcholine release controls cue detection on multiple timescales. Neuron 56:141-154.

Parikh V, St. Peters M, Blakely RD, Sarter M (2013) The presynaptic choline transporter imposes limits on sustained cortical acetylcholine release and attention. J Neurosci 33:2326-2337.

Parikh V, Apparsundaram S, Kozak R, Richards JB, Sarter M (2006) Reduced expression and capacity of the striatal high-affinity choline transporter in hyperdopaminergic mice. Neuroscience 141:379-389.

Parikh V, Pomerleau F, Huettl P, Gerhardt GA, Sarter M, Bruno JP (2004) Rapid assessment of in vivo cholinergic transmission by amperometric detection of changes in extracellular choline levels. Eur J Neurosci 20:1545-1554.

Perry RJ, Hodges JR (1999) Attention and executive deficits in Alzheimer's disease. A critical review. Brain 122 ( Pt 3):383-404.

Ray A, Lindahl E, Wallner B (2010) Model quality assessment for membrane proteins. Bioinformatics 26:3067-3074.

Sarkar A, Kellogg GE (2010) Hydrophobicity--shake flasks, protein folding and drug discovery. Curr Top Med Chem 10:67-83.

Sarter M, Parikh V (2005) Choline transporters, cholinergic transmission and cognition. Nat Rev Neurosci 6:48-56.

Sarter M, Fritschy JM (2008) Reporting statistical methods and statistical results in EJN. Eur J Neurosci 28:2363-2364.

Sarter M, Lustig C (2020) Forebrain Cholinergic Signaling: Wired and Phasic, Not Tonic, and Causing Behavior. J Neurosci 40:712-719. 
Sarter M, Lustig C, Blakely RD, Koshy Cherian A (2016) Cholinergic genetics of visual attention: Human and mouse choline transporter capacity variants influence distractibility. J Physiol Paris 110:10-18.

Sarter M, Avila C, Kucinski A, Donovan E (2021) Make a Left Turn: Cortico-Striatal Circuitry Mediating the Attentional Control of Complex Movements. Mov Disord 36:535-546.

Simon JR, Atweh S, Kuhar MJ (1976) Sodium-dependent high affinity choline uptake: a regulatory step in the synthesis of acetylcholine. J Neurochem 26:909-922.

Stamm M, Staritzbichler R, Khafizov K, Forrest LR (2013) Alignment of helical membrane protein sequences using AlignMe. PLoS One 8:e57731.

Stamm M, Staritzbichler R, Khafizov K, Forrest LR (2014) AlignMe--a membrane protein sequence alignment web server. Nucleic Acids Res 42:W246-251.

Tehovnik EJ, Sommer MA (1997) Effective spread and timecourse of neural inactivation caused by lidocaine injection in monkey cerebral cortex. J Neurosci Methods 74:17-26.

Thienel R, Kellermann T, Schall U, Voss B, Reske M, Halfter S, Sheldrick AJ, Radenbach K, Habel U, Shah NJ, Kircher T (2009) Muscarinic antagonist effects on executive control of attention. Int J Neuropsychopharmacol 12:1307-1317.

Tsirigos KD, Peters C, Shu N, Kall L, Elofsson A (2015) The TOPCONS web server for consensus prediction of membrane protein topology and signal peptides. Nucleic Acids Res 43:W401407.

Turchi J, Sarter M (1997) Cortical acetylcholine and processing capacity: effects of cortical cholinergic deafferentation on crossmodal divided attention in rats. Cogn Brain Res 6:147158.

Turchi J, Sarter M (2000) Cortical cholinergic inputs mediate processing capacity: effects of 192 IgG-saporin-induced lesions on olfactory span performance. Eur J Neurosci 12:45054514.

Venkatesan S, Lambe EK (2020) Chrna5 is Essential for a Rapid and Protected Response to Optogenetic Release of Endogenous Acetylcholine in Prefrontal Cortex. J Neurosci 40:7255-7268.

Voytko ML, Olton DS, Richardson RT, Gorman LK, Tobin JR, Price DL (1994) Basal forebrain lesions in monkeys disrupt attention but not learning and memory. J Neurosci 14:167-186.

Wang $\mathrm{H}$ et al. (2017) Choline transporter mutations in severe congenital myasthenic syndrome disrupt transporter localization. Brain 140:2838-2850.

Webb B, Sali A (2016) Comparative protein structure modeling using MODELLER. Curr Protoc Protein Sci 86:2.9.1-2.9.37.

Yamamura HI, Snyder SH (1972) Choline: high-affinity uptake by rat brain synaptosomes. Science 178:626-628.

Yarnall A, Rochester L, Burn DJ (2011) The interplay of cholinergic function, attention, and falls in Parkinson's disease. Mov Disord 26:2496-2503.

Zimmermann L, Stephens A, Nam SZ, Rau D, Kubler J, Lozajic M, Gabler F, Soding J, Lupas AN, Alva V (2018) A Completely Reimplemented MPI Bioinformatics Toolkit with a New HHpred Server at its Core. J Mol Biol 430:2237-2243. 
bioRxiv preprint doi: https://doi.org/10.1101/2021.06.27.450076; this version posted June 28, 2021. The copyright holder for this preprint (which was not certified by peer review) is the author/funder. All rights reserved. No reuse allowed without permission.

Figure 1
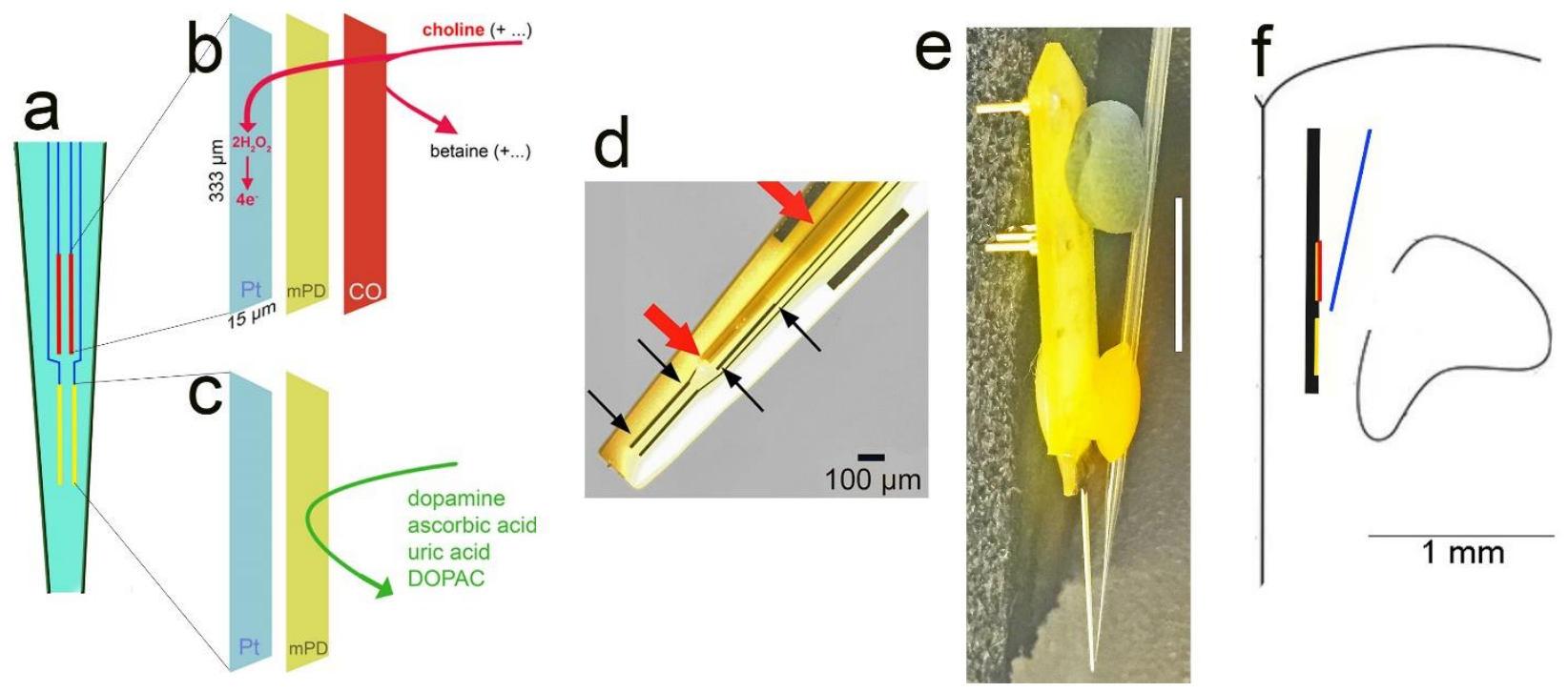
bioRxiv preprint doi: https://doi.org/10.1101/2021.06.27.450076; this version posted June 28, 2021. The copyright holder for this preprint (which was not certified by peer review) is the author/funder. All rights reserved. No reuse allowed without permission.

Figure 2
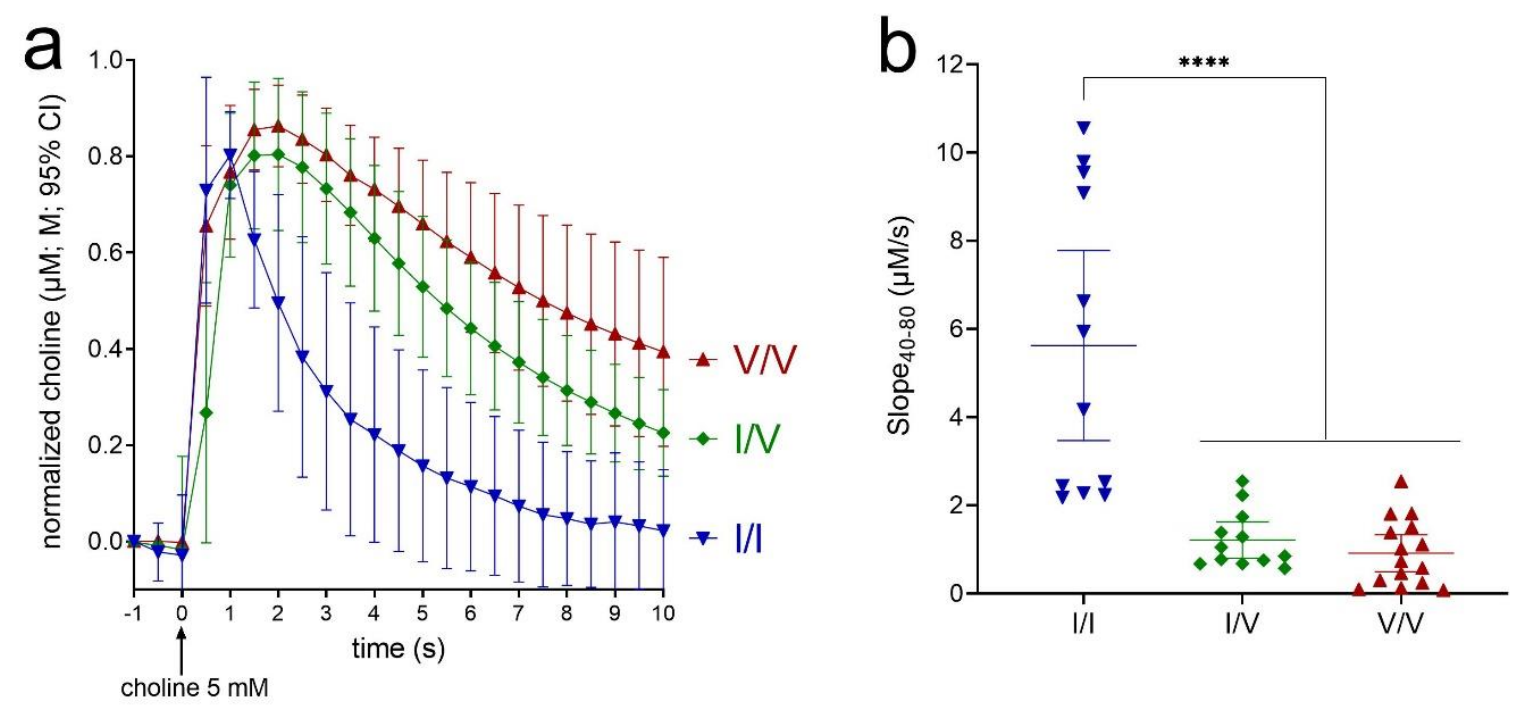
bioRxiv preprint doi: https://doi.org/10.1101/2021.06.27.450076; this version posted June 28, 2021. The copyright holder for this preprint (which was not certified by peer review) is the author/funder. All rights reserved. No reuse allowed without permission.

\section{Figure 3}
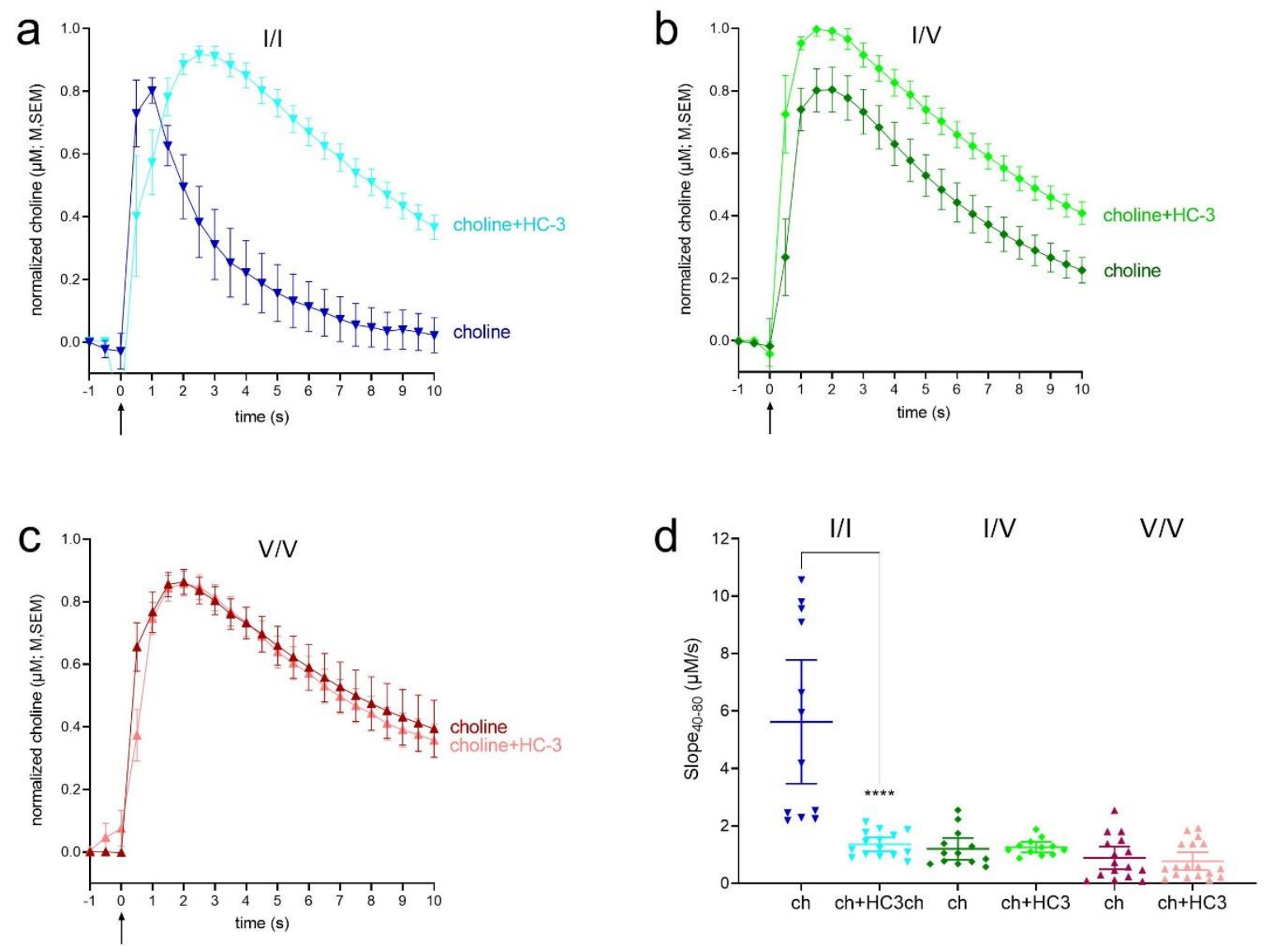
Figure 4

a

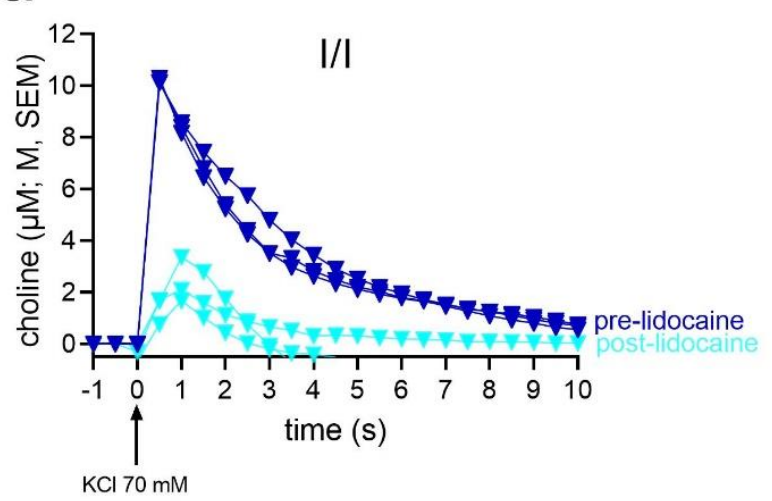

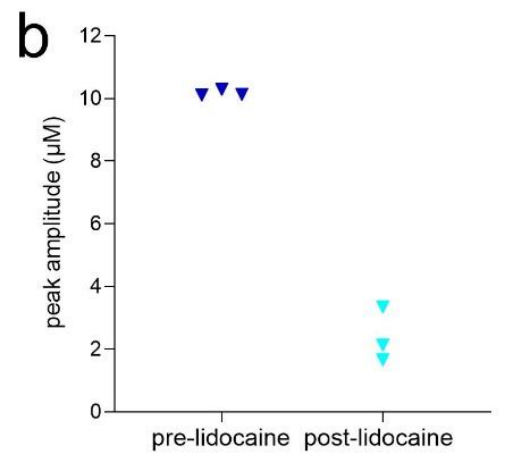
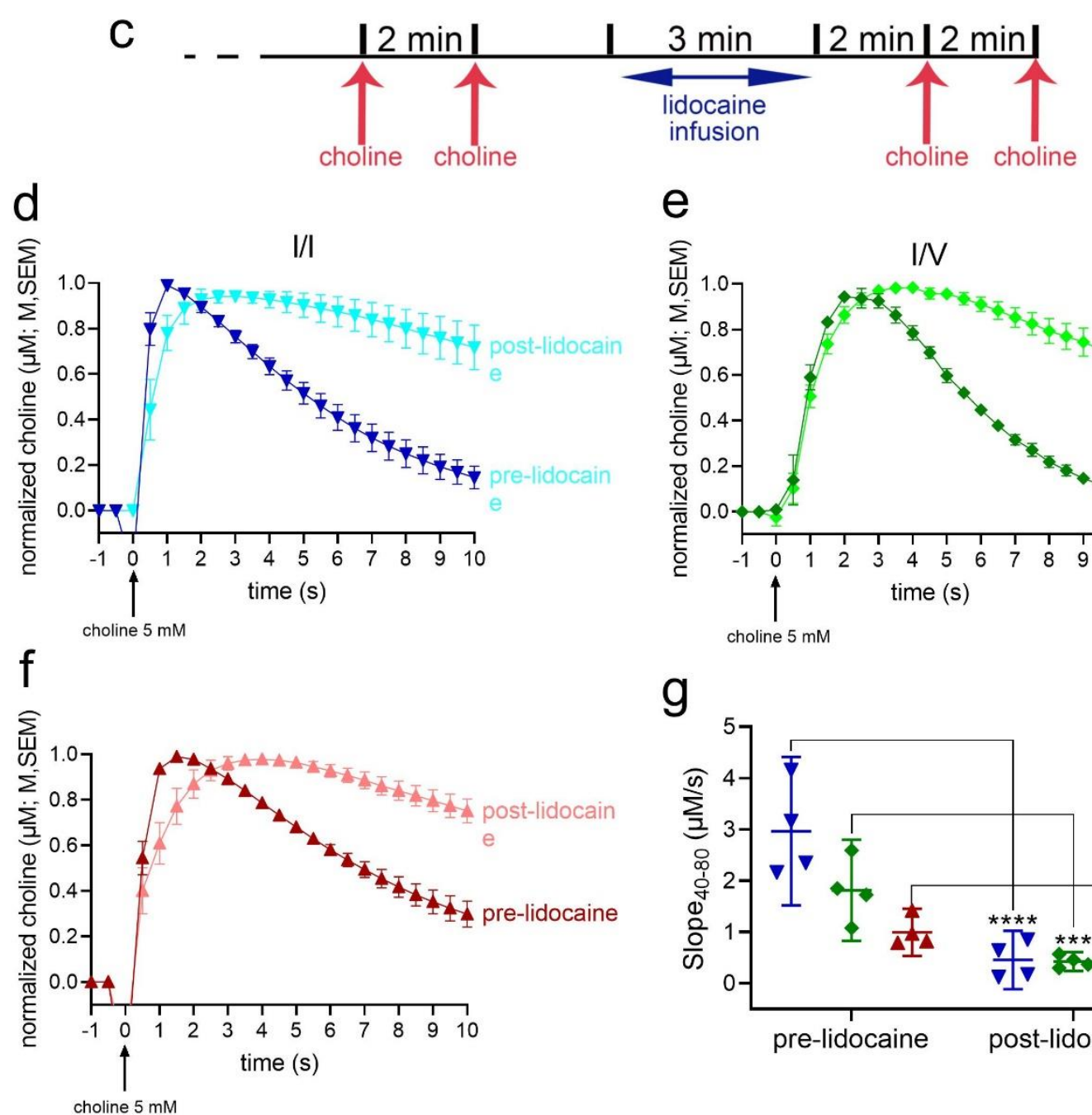

e

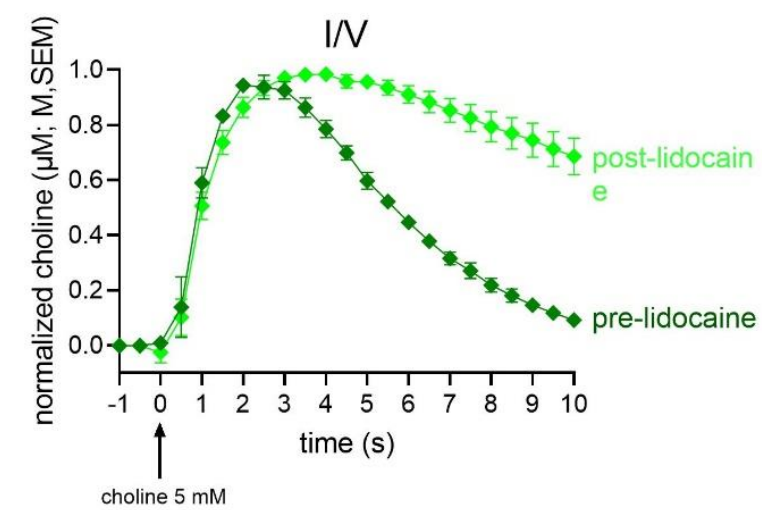

g

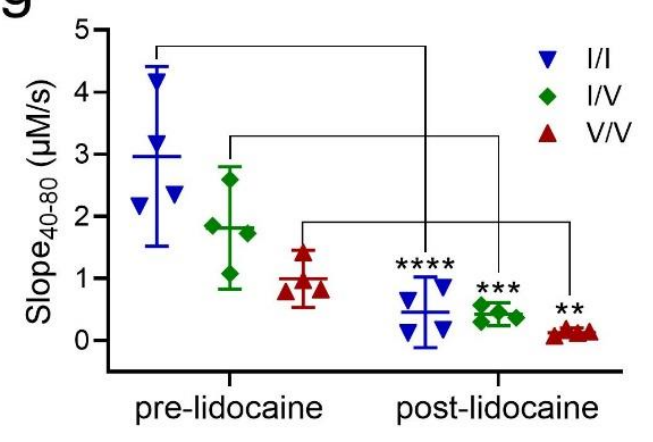


Figure 5

a
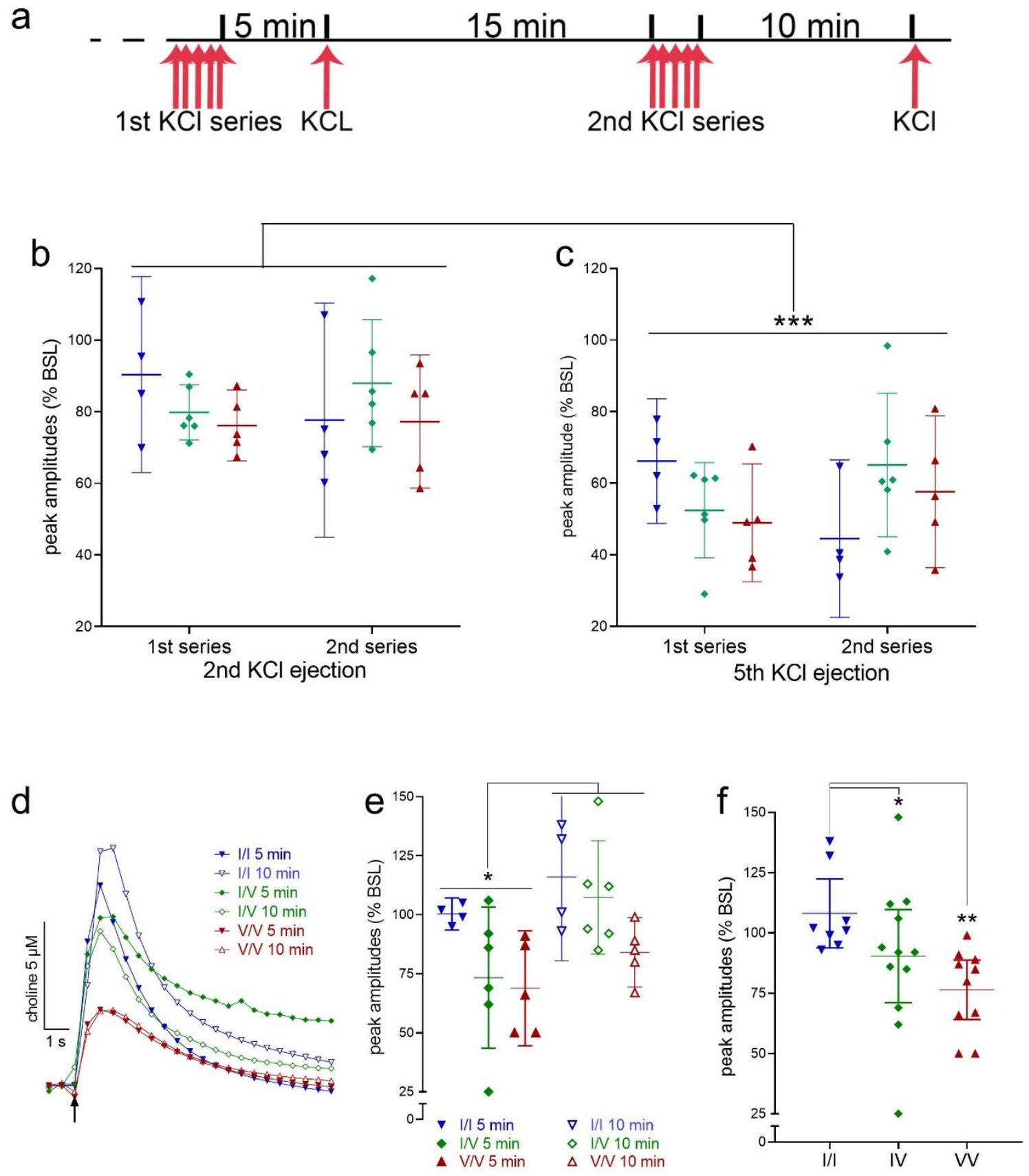
Figure 6

a
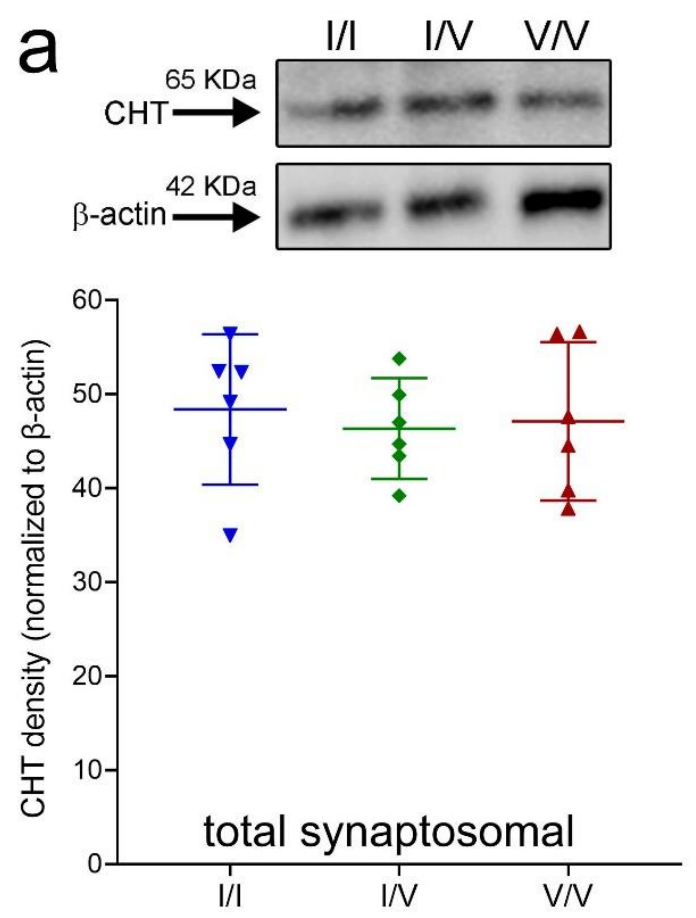
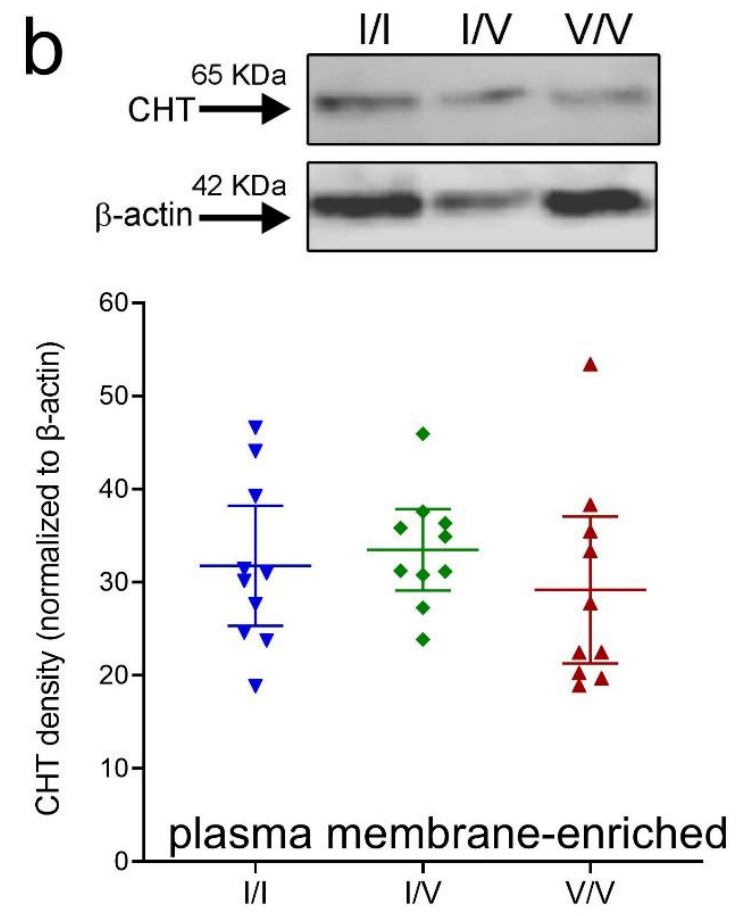
bioRxiv preprint doi: https://doi.org/10.1101/2021.06.27.450076; this version posted June 28, 2021. The copyright holder for this preprint (which was not certified by peer review) is the author/funder. All rights reserved. No reuse allowed without permission.

Figure 7

A

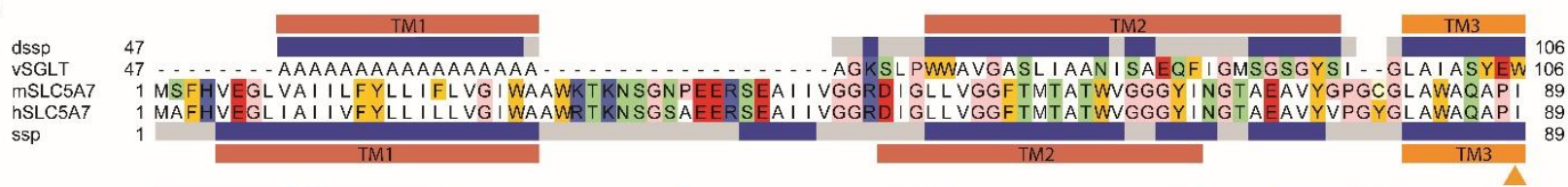

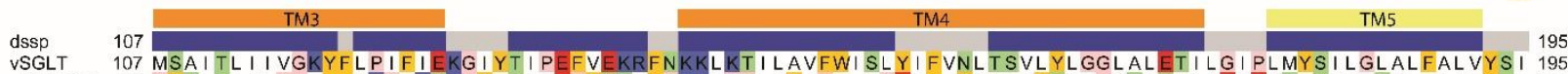

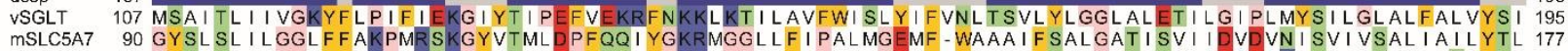

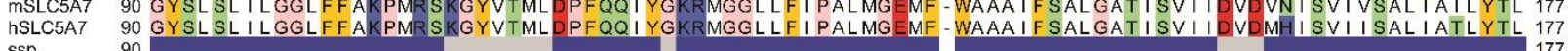
ssp TM3 TM4 TMS

dssp 196 TM6 284 VSGLT 196 YGGL SAVVWTDVIQVFFLVLGGFMT TYMAVSF I GGTDGWFAGVS KMVDAAPGHFEMILDQSNPQYMNL PG IAVL I GGLWVANL YYWGFN 284

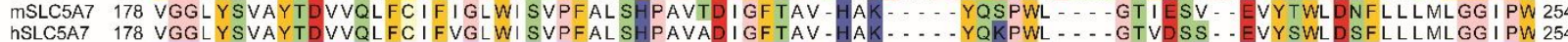
sSp 178 THA 254 \begin{tabular}{c|ccc} 
TMS & TM6 & TM7 \\
\hline
\end{tabular}

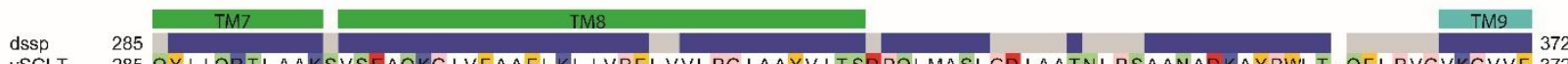
VSGLT 285 OY I IQRTL AAKSVSEAQKG I VFAAFLKL I VPFLVVLPG I AAYVI I SDPQL MASLGDI AATNLPSAANADKAYPWL T-OFLLPGVKGVVF 372 MSLC5A7 255 QAYFQRVLSSSSATYAQVLSFLAAFGCLVMALPAICIGAIGASTDUNQTA - - - YG - - - YPDPKTKEEADMILPIVLQYLCPVYISFFGL 337 $\begin{array}{ll}\text { hSLC5A7 } & 255 \\ \text { SSP } & 255\end{array}$

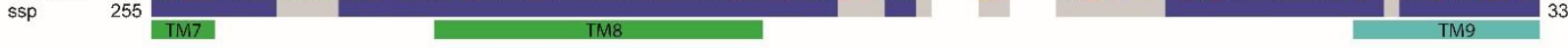

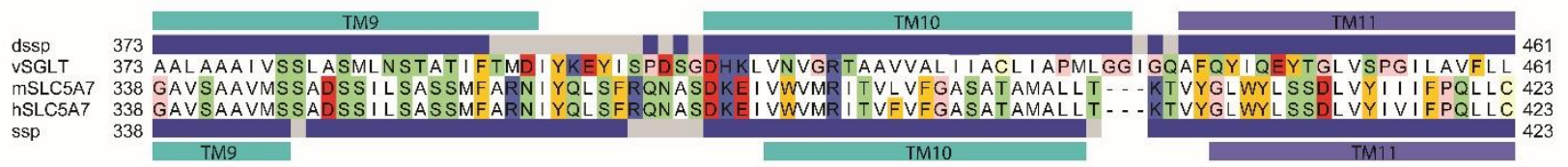
hSLC5A7 338 GAVSAAVMSSADSSI LSASSMFARN I YQL SFRQNASDKEI VWVMRI TVFVFGASATAMALLT - - - KTVYGLWYLSSDLVYIVIFPQLLC 423

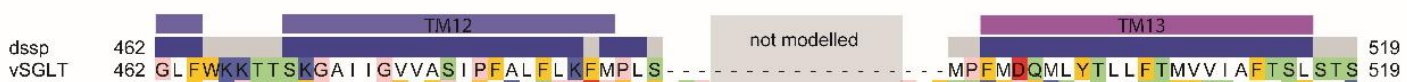

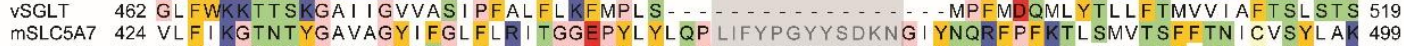

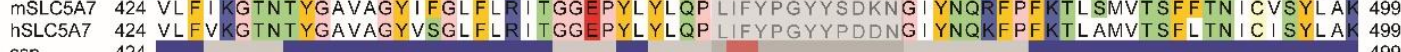
424 TM12

$\mathrm{B}$

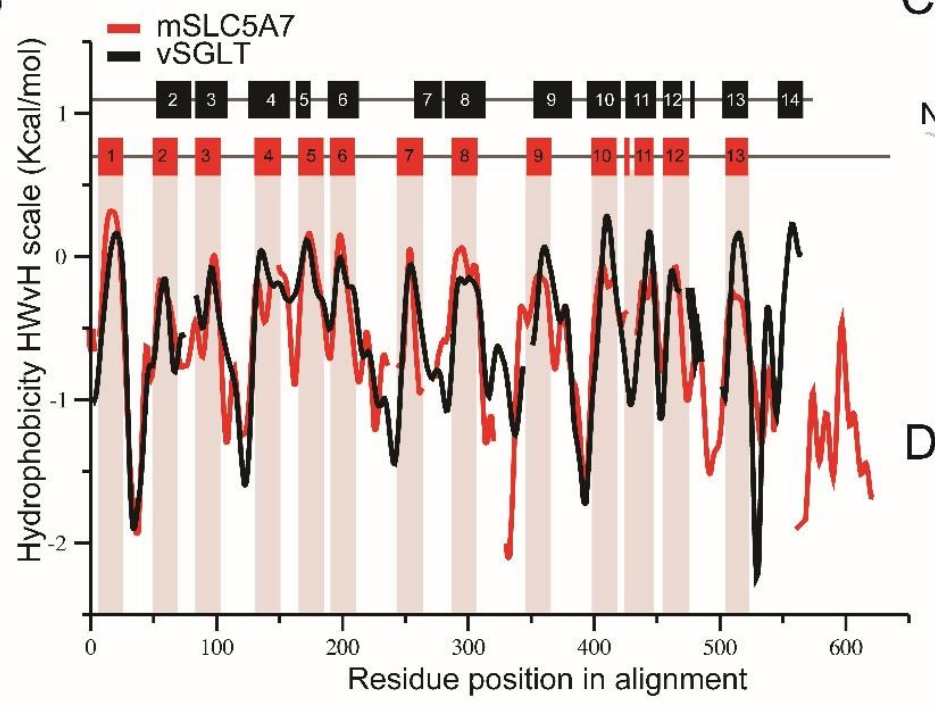

C

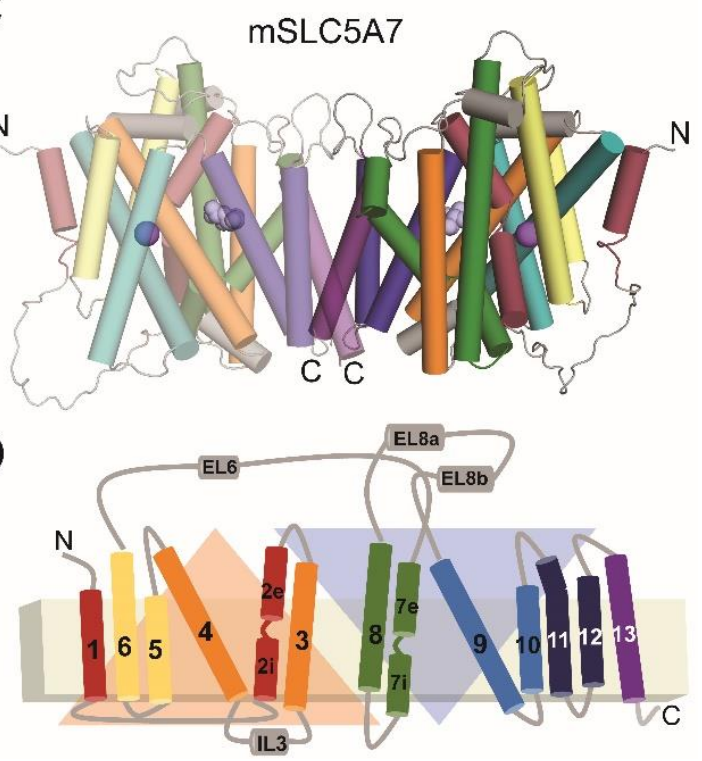


Figure 8

A

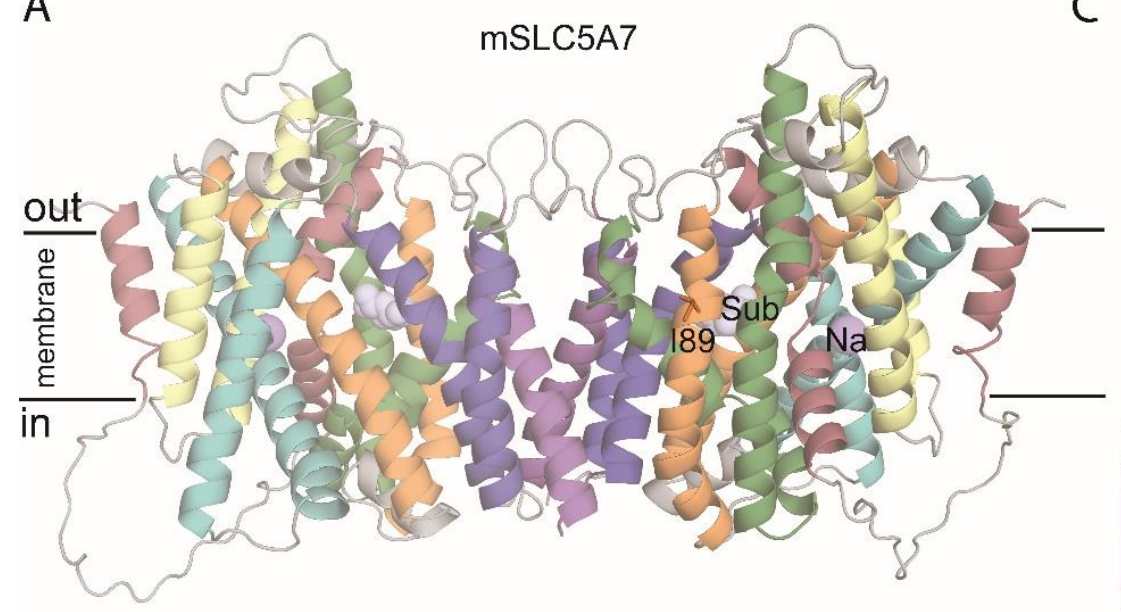

B

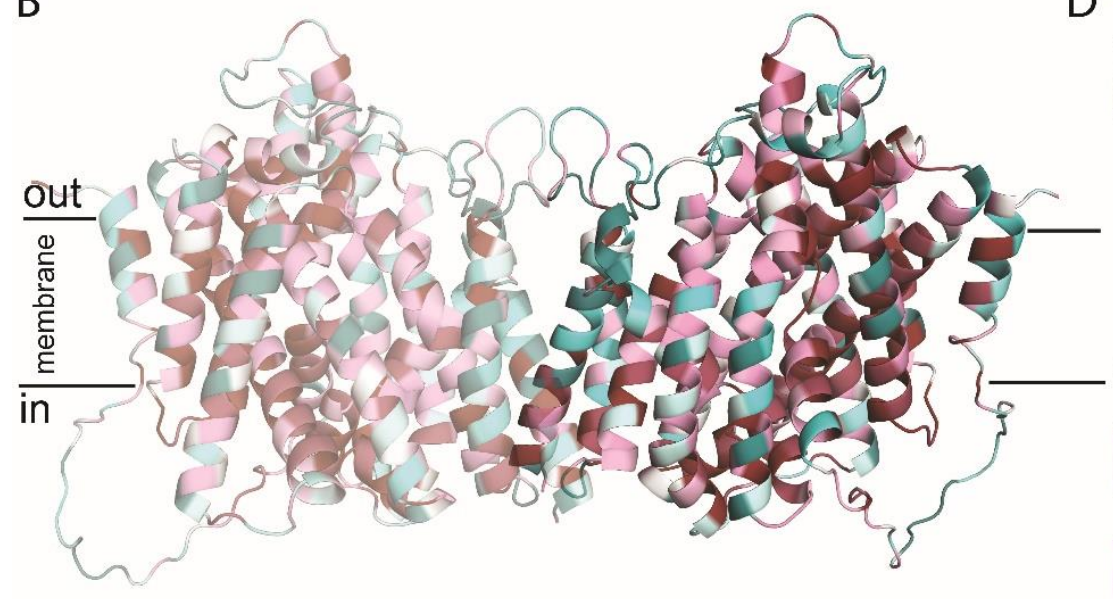

C

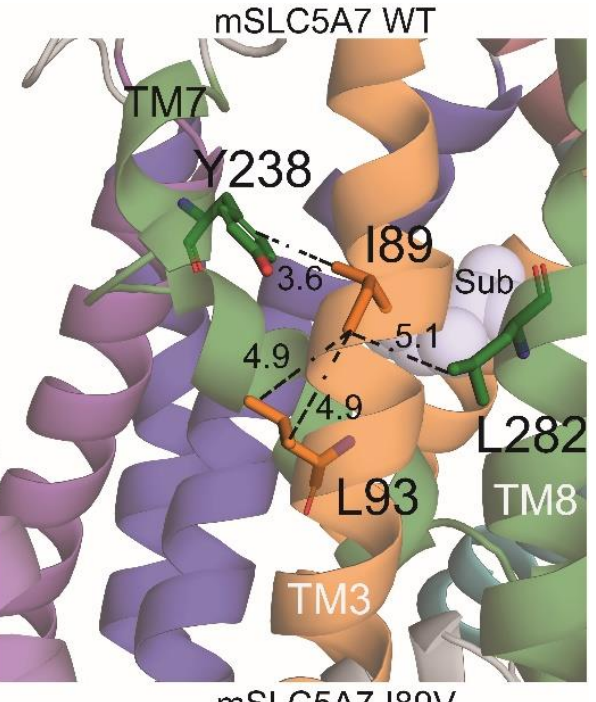

D

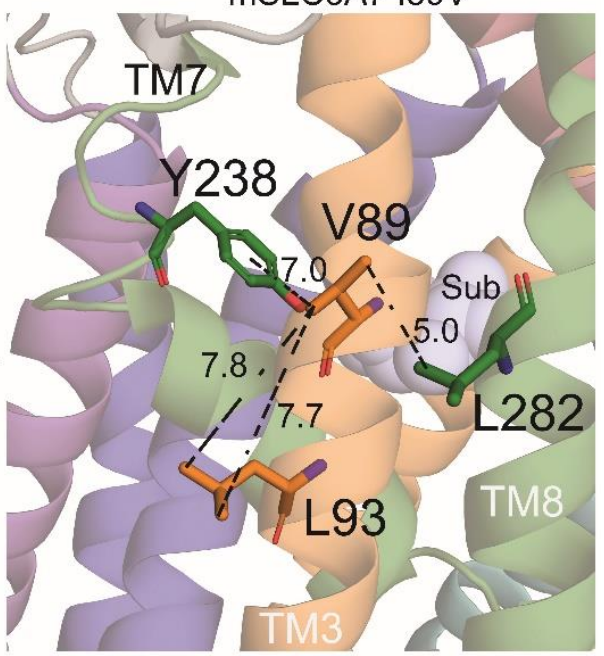

